\title{
Modeling organic aerosols in a megacity: comparison of simple and complex representations of the volatility basis set approach
}

\author{
M. Shrivastava ${ }^{1}$, J. Fast ${ }^{1}$, R. Easter ${ }^{1}$, W. I. Gustafson Jr. ${ }^{1}$, R. A. Zaveri ${ }^{1}$, J. L. Jimenez ${ }^{2}$, P. Saide ${ }^{3}$, and A. Hodzic ${ }^{4}$ \\ ${ }^{1}$ Atmospheric Sciences \& Global Change Division, Pacific Northwest National Laboratory, Richland, WA 99352, USA \\ ${ }^{2}$ University of Colorado, Boulder, CO, USA \\ ${ }^{3}$ Center for Global and Regional Environmental Research, University of Iowa, Iowa City, Iowa, USA \\ ${ }^{4}$ National Center for Atmospheric Research, Boulder, CO, USA
}

Received: 20 October 2010 - Published in Atmos. Chem. Phys. Discuss.: 10 December 2010

Revised: 6 May 2011 - Accepted: 29 June 2011 - Published: 13 July 2011

\begin{abstract}
The Weather Research and Forecasting model coupled with chemistry (WRF-Chem) is modified to include a volatility basis set (VBS) treatment of secondary organic aerosol formation. The VBS approach, coupled with SAPRC-99 gas-phase chemistry mechanism, is used to model gas-particle partitioning and multiple generations of gas-phase oxidation of organic vapors. In addition to the detailed 9-species VBS, a simplified mechanism using 2 volatility species (2-species VBS) is developed and tested for similarity to the 9-species VBS in terms of both mass and oxygen-to-carbon ratios of organic aerosols in the atmosphere. WRF-Chem results are evaluated against field measurements of organic aerosols collected during the MILAGRO 2006 campaign in the vicinity of Mexico City. The simplified 2-species mechanism reduces the computational cost by a factor of 2 as compared to 9-species VBS. Both ground site and aircraft measurements suggest that the 9-species and 2-species VBS predictions of total organic aerosol mass as well as individual organic aerosol components including primary, secondary, and biomass burning are comparable in magnitude. In addition, oxygen-to-carbon ratio predictions from both approaches agree within $25 \%$, providing evidence that the 2-species VBS is well suited to represent the complex evolution of organic aerosols. Model sensitivity to amount of anthropogenic semi-volatile and intermediate volatility (S/IVOC) precursor emissions is also examined by doubling the default emissions. Both the emission cases significantly under-predict primary organic aerosols in the city center and along aircraft flight transects. Secondary organic aerosols are predicted reasonably well along flight tracks surrounding the city, but are consistently over-predicted downwind of the city. Also, oxygen-to-carbon ratio predictions are
\end{abstract}

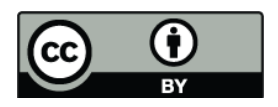

Correspondence to: M. Shrivastava (manishkumar.shrivastava@pnl.gov) significantly improved compared to prior studies by adding $15 \%$ oxygen mass per generation of oxidation; however, all modeling cases still under-predict these ratios downwind as compared to measurements, suggesting a need to further improve chemistry parameterizations of secondary organic aerosol formation.

\section{Introduction}

Organic aerosol (OA) comprises a large fraction (20 to $90 \%$ ) of submicron particulate matter in the atmosphere affecting radiative climate forcing and human health (Murphy et al., 2006; Zhang et al., 2007). Accurate representation of OA in models requires a good understanding of processes leading to formation and removal of OA in the atmosphere. OA is composed of directly emitted primary organic aerosols (POA) and photochemically produced secondary organic aerosols (SOA). POA is emitted from a variety of sources such as fossil fuel and biomass burning.

POA has traditionally been considered as non-volatile and non-reactive in air quality models. However, recently Robinson et al. (2007) showed that instead of a static fixed nonvolatile mass, POA is a dynamic system formed due to gasparticle mass transfer of a multi-component mixture of semivolatile organic species evolving as a function of atmospheric variables such as dilution, temperature, and pre-existing OA as predicted by absorptive partitioning theory (Shrivastava et al., 2006). Thus, the conceptual model of Robinson et al. (2007) emits organic precursors which are lumped into nine surrogate volatility species separated by factor of 10 at $298 \mathrm{~K}$ (volatility basis set or VBS) classified as: (1) Semivolatile organic compounds (SVOC) with effective saturation concentrations $\left(C^{*}\right)$ ranging $10^{-2}$ to $10^{3} \mu \mathrm{g} \mathrm{m} \mathrm{m}^{-3}$ and (2) Intermediate volatility organic compounds (IVOC) with $C^{*}$

Published by Copernicus Publications on behalf of the European Geosciences Union. 
ranging $10^{4}$ to $10^{6} \mu \mathrm{g} \mathrm{m}^{-3}$. A substantial portion of SVOC mass will partition to POA in the atmosphere, while in the absence of photochemistry, the IVOC species remain as organic vapors under most atmospheric conditions. This multicomponent mixture of SVOC and IVOC (S/IVOC) species is assumed to undergo gas-phase photochemical oxidation by $\mathrm{OH}$ radicals resulting in formation of successively lower volatility species, which may condense to form SOA (Robinson et al., 2007; Shrivastava et al., 2006).

SOA formation also occurs through gas-phase oxidation of volatile organic compounds (VOCs with $C^{*}$ greater than $10^{7} \mu \mathrm{g} \mathrm{m}^{-3}$ ) such as biogenic VOCs (e.g., terpenes and isoprene) and traditional anthropogenic VOCs (e.g., aromatics and higher MW alkanes and olefins) (Tsimpidi et al., 2010). However, SOA formation through oxidation of S/IVOC precursors is thought to be more efficient as compared to VOC precursors, as S/IVOC species have lower volatility favoring partitioning to the particle phase after oxidation (Donahue et al., 2006). SOA formed due to photochemical oxidation of S/IVOC precursors is named "SI-SOA", while oxidation of biogenic/traditional anthropogenic VOCs forms "V-SOA".

Aerosol Mass Spectrometer (AMS) measurements and subsequent analysis with Positive Matrix Factorization (PMF) classify total OA as hydrocarbon-like OA (HOA representing fresh primary OA), and oxygenated OA (OOA representing OA formed after chemical oxidation in the atmosphere) (Ulbrich et al., 2009). HOA and OOA have been shown to be good surrogates of urban POA and total SOA respectively in the atmosphere (Zhang et al., 2007). Recent results show that SOA accounts for a large fraction of OA burden throughout the atmosphere with its fraction of total OA increasing from urban to remote continental locations (Zhang et al., 2007). Previous "bottom up" chemical transport models based on parameterizations derived from laboratory experiments severely under-predicted the magnitude and evolution of SOA in polluted regions (de Gouw et al., 2005; Goldstein and Galbally, 2007; Hallquist et al., 2009; Heald et al., 2005; Volkamer et al., 2006), while predictions in unpolluted biogenically-dominated regions do not show a similar under-prediction (Slowik et al., 2010; Tunved et al., 2006). Recent modeling efforts have significantly increased the amount of SOA modeled in polluted regions, bringing model predictions closer to measurements (Dzepina et al., 2009; Hodzic et al., 2010). Using a box model and data from the MCMA-2003 campaign, Dzepina et al. (2009) combined different modeling approaches to close the gap between model and measurements for SOA. Dzepina et al. (2009) found that SI-SOA accounted for about half of the observed SOA mass. However, large uncertainties remain in terms of various model parameters and other SOA formation pathways and yields. Recently some models have been proposed which "age" semi-volatiles formed in V-SOA mechanisms by gas-phase reaction, as in e.g. Tsimpidi et al. (2010). Dzepina et al. (2011) recently reported that the Tsimpidi et al. (2010) A-V-SOA mechanism produces enough SOA to match the regional observations, and that a large SOA over-prediction is observed when SI-SOA is also implemented.

In addition to mass, aerosol hygroscopicity is an important parameter affecting direct and indirect radiative forcing of climate. The hygroscopicity parameter $\kappa$ was recently shown to be directly related to elemental oxygen to carbon molar ratios of OA (O:C ratio) for ambient aerosols in urban, remote and forest locations (Jimenez et al., 2009). Most of the largescale chemical transport models are not designed to represent the O:C ratio of OA due to complexity of processes involved. Prediction of $\mathrm{O}: \mathrm{C}$ ratios also requires separate tracers for carbon and oxygen species for both freshly emitted and oxidized organic species in the atmosphere, with each class of organics (such as fresh, oxidized) being represented by a separate VBS of 8 or 9 volatility intervals (Hodzic et al., 2010; Shrivastava et al., 2008). In chemical transport models, advection of this large set of organic species requires more computational time than chemistry and gas-particle partitioning combined. Models running online meteorology, such as the Weather Research and Forecasting Model coupled to chemistry (WRF-Chem) (Grell et al., 2005), are especially susceptible to this large computational burden as compared to offline representations of meteorology in chemical-transport models, such as CHIMERE (Hodzic et al., 2009) and CMAQ (Carlton et al., 2010), because the advection time step is similar for meteorology and chemistry. An important advantage of online models is that they permit aerosol-radiation-cloudchemistry interaction processes and the associated feedback effects on meteorology to be simulated, whereas offline models cannot study these processes.

The objectives of this work are to: (1) implement a detailed OA mechanism in WRF-Chem based on a 9species VBS that includes SOA formation from S/IVOC precursors (Robinson et al., 2007) and traditional anthropogenic/biogenic VOCs; (2) modify the ROB mechanism in terms of oxygen added per generation of oxidation and test predictions of O:C ratios; (3) develop a highly condensed 2 -species SOA mechanism and evaluate it in terms of performance and computational speed compared to the more detailed VBS mechanism; and (4) evaluate the OA mechanisms using field measurements of organic aerosols collected during the 2006 MILAGRO field campaign in the vicinity of Mexico City.

We will show that it is possible to successfully develop highly condensed OA mechanisms that give very similar results to the detailed VBS mechanisms and are more suitable for real-time forecasting and climate model applications. It is also extremely important to test simplified organic aerosol mechanisms using a model configuration that can resolve much of the temporal and spatial variations of observed organic aerosols, before these mechanisms are routinely used in global models with coarse spatial resolution that are difficult to evaluate using point measurements. The terminology used for various classes of organic species used in this study is described in Table 1 for reference. 
Table 1. Terminology used for various classes of organic species in this study.

\begin{tabular}{|c|c|}
\hline \multicolumn{2}{|r|}{ Gas phase organic compounds } \\
\hline SVOC & $\begin{array}{l}\text { Semi-Volatile Organic Compounds: primary organic vapors which have suf- } \\
\text { ficiently low vapor pressure to dynamically partition between the gas and the } \\
\text { aerosol phases (Robinson et al., 2007) i.e. } 10^{-2} \leq C^{*} \leq 10^{3} \mu \mathrm{g} \mathrm{m}^{-3} \text { at } 298 \mathrm{~K} \\
\text { and } 1 \mathrm{~atm}\end{array}$ \\
\hline IVOC & $\begin{array}{l}\text { Intermediate Volatility Organic Compounds: primary organic vapors with } \\
\text { volatility higher than SVOC but lower than traditional VOCs i.e. } 10^{4} \leq \\
C^{*} \leq 10^{6} \mu \mathrm{g} \mathrm{m}^{-3} \text { at } 298 \mathrm{~K} \text { and } 1 \mathrm{~atm} \text { (Robinson et al., 2007) }\end{array}$ \\
\hline S/IVOC & $\mathrm{SVOC}+\mathrm{IVOC}$ \\
\hline VOC & $\begin{array}{l}\text { Volatile Organic Compounds: gas-phase organic species with volatility higher } \\
\text { than S/IVOC i.e. } C^{*} \geq 10^{7} \mu \mathrm{g} \mathrm{m}^{-3} \text { at } 298 \mathrm{~K} \text { and } 1 \mathrm{~atm} \text { (e.g. toluene, isoprene, } \\
\text { terpenes). }\end{array}$ \\
\hline \multicolumn{2}{|r|}{ Condensed phase organics } \\
\hline $\mathrm{OA}$ & $\begin{array}{l}\text { Organic Aerosol: includes both primary and secondary mass components } \\
\text { (POA + SOA defined below). }\end{array}$ \\
\hline POA & $\begin{array}{l}\text { Primary Organic Aerosol: defined as organic aerosol either directly emitted or } \\
\text { formed due to condensation of organic vapors before photochemical oxidation } \\
\text { in the atmosphere. }\end{array}$ \\
\hline SOA & $\begin{array}{l}\text { Secondary Organic Aerosol: defined as organic aerosol formed after photo- } \\
\text { chemical oxidation and condensation of organic vapors (V-SOA + SI-SOA) in } \\
\text { the atmosphere }\end{array}$ \\
\hline V-SOA & $\begin{array}{l}\text { Component of SOA formed due to photochemical oxidation of all VOC } \\
\text { precursors (A-V-SOA + B-V-SOA described below) }\end{array}$ \\
\hline A-V-SOA & $\begin{array}{l}\text { Component of SOA formed due to photochemical oxidation of traditional an- } \\
\text { thropogenic VOC precursors (e.g. ARO1, ARO2, ALK4 etc.) }\end{array}$ \\
\hline B-V-SOA & $\begin{array}{l}\text { Component of SOA formed due to photochemical oxidation of biogenic VOC } \\
\text { precursors (e.g. isoprene, monoterpenes, sesquiterpenes) }\end{array}$ \\
\hline SI-SOA & $\begin{array}{l}\text { Component of SOA formed due to photochemical oxidation of all S/IVOC pre- } \\
\text { cursors (A-SI-SOA + BB-SI-SOA) }\end{array}$ \\
\hline A-SI-SOA & $\begin{array}{l}\text { Component of SOA formed due to photochemical oxidation of anthropogenic } \\
\text { S/IVOC precursors (e.g. traffic emissions, municipal trash burning) }\end{array}$ \\
\hline BB-SI-SOA & $\begin{array}{l}\text { Component of SOA formed due to photochemical oxidation of biomass burning } \\
\text { S/IVOC precursors }\end{array}$ \\
\hline \multicolumn{2}{|r|}{ Aerosol mass spectrometer terminology } \\
\hline $\mathrm{HOA} \leftrightarrow \mathrm{POA}$ & $\begin{array}{l}\text { Hydrocarbon-like Organic Aerosols: an OA component identified with PMF } \\
\text { which is consistent with mass spectral signatures of reduced species such as } \\
\text { those from motor vehicle emissions. It is generally understood as a } \\
\text { surrogate for urban combustion-related POA (Ulbrich et al., 2009). }\end{array}$ \\
\hline $\mathrm{OOA} \leftrightarrow \mathrm{SOA}$ & $\begin{array}{l}\text { Oxygenated Organic Aerosols: an OA component identified with PMF which } \\
\text { is characterized by its high oxygen content. It is generally understood as a } \\
\text { surrogate for SOA from all sources. }\end{array}$ \\
\hline BBOA & $\begin{array}{l}\text { Biomass Burning Organic Aerosols: an OA component identified with PMF } \\
\text { which is characterized by spectral features typical of biomass smoke. It is } \\
\text { thought to be dominated by biomass burning POA, while biomass burning SOA } \\
\text { is mostly apportioned into the OOA component. }\end{array}$ \\
\hline
\end{tabular}

\section{Model description}

Version 3.1.1 of the WRF-Chem community model is used to simulate the atmospheric conditions between 6 and 30 March 2006 over Mexico. Trace gases and aerosols are simulated simultaneously with meteorology (Grell et al., 2005). WRFChem includes several options for gas-phase chemistry and aerosols. In this study, gas-phase chemistry is represented by the SAPRC-99 mechanism (Carter, 2000a,b), and the aerosol lifecycle processes are represented by the MOSAIC aerosol 
module (Zaveri et al., 2008). Aerosol species in MOSAIC includes sulfate, nitrate, ammonium, sodium, chloride, calcium, carbonate, other inorganics (i.e. dust), methanesulfonate, elemental carbon, organic matter, and aerosol water; however, until now organic matter has been treated as nonvolatile POA. Additional details of the WRF-Chem model as applied in this study have been described previously (Fast et al., 2009). Here, only processes and modifications to WRFChem relevant to simulating organic aerosol components are described in detail. The 9-species VBS mechanism for organic aerosols implemented in WRF-Chem is described first, followed by a discussion of the assumptions needed to develop a condensed 2-species mechanism.

\subsection{Detailed 9-species VBS mechanism for OA}

The 9-species VBS mechanism for POA and non-traditional SOA implemented in WRF-Chem is similar to that described by Robinson et al. (2007) and Shrivastava et al. (2008), with modifications for global non-volatile fraction and amount of oxygen added per generation of oxidation as described later. Previous studies have already implemented versions of this mechanism using offline meteorological models (Hodzic et al., 2010; Tsimpidi et al., 2010).

The mechanism treats POA described by 9 surrogate species with $C^{*}$ values (at $298 \mathrm{~K}$ and $1 \mathrm{~atm}$ ) of $10^{-2}, 10^{-1}$, $10^{0}, 10^{1}, 10^{2}, 10^{3}, 10^{4}, 10^{5}, 10^{6} \mathrm{\mu g} \mathrm{m}^{-3}$. For each surrogate species, we treat both the aerosol phase species (in 4 size bins for this study) and the gas phase species. The bin boundaries for the size bins are 0.0391, 0.156, 0.625, 2.50, and $10.0 \mu \mathrm{m}$ (dry diameter). Aerosol phase species for higher volatility $\left(>10^{4} \mu \mathrm{g} \mathrm{m}^{-3}\right)$ could be neglected with little effect on OA predictions, but were included for completeness. In future applications, aerosol species of higher volatility would be excluded from WRF-Chem to save computational time. The POA species are segregated by two emissions sectors: biomass burning and anthropogenic (predominately fossil fuel). To allow calculating O:C ratios for the modeled OA, separate model species are used for the oxygen and non-oxygen $(\mathrm{C}, \mathrm{H}, \mathrm{N})$ components of each species. This gives the following POA species:

- $\operatorname{POA}(\mathrm{a})_{i, e, x, n}=$ aerosol-phase POA, where $\mathrm{i}$ is the volatility species (1-9), e is either the biomass or anthropogenic emission sector, $\mathrm{x}$ is either the oxygen or non-oxygen component, and $\mathrm{n}$ is the size bin (1-4).

- POA $(\mathrm{g})_{i, e, x}=$ corresponding gas-phase POA species.

Partitioning between the gas and aerosol phase species is calculated using absorptive partitioning theory assuming thermodynamic equilibrium approach as described by Donahue et al. (2006).

The O:C ratio of bulk particulate OA evolves as a function of emissions of fresh primary organic material, oxidation of organic vapors with addition of oxygen mass after each generation of oxidation (Robinson et al., 2007), gasparticle partitioning varying with ambient factors such as temperature, dilution and OA concentrations, and removal rates of $\mathrm{OA}$ and gas-phase semi-volatiles due to dry and wet deposition. An OM/OC (organic mass to organic carbon ratio) of 1.57 and 1.25 for biomass burning and anthropogenic emissions respectively is assumed, converting $\mathrm{OM}$ emission rates to $\mathrm{OC}$. Elemental $\mathrm{O}: \mathrm{C}$ ratios of 0.3 and 0.06 are assumed for fresh biomass burning and anthropogenic emissions for calculating the oxygen fraction of each species. In addition, non-oxygen (carbon, hydrogen and nitrogen) to carbon ratio of 1.17 was assumed for all species. These assumptions are consistent with PMF analysis of ambient AMS data by Aiken et al. (2008) in Mexico City. The sum of oxygen and non-oxygen parts for each species equals total OM input to WRF-Chem, thus all OM mass is accounted for in the gas-particle partitioning calculations. The gas-phase POA species react with $\mathrm{OH}$ to produce more-oxygenated and lower-volatility SI-SOA species, as described in Sect. 2.1.2.2. These SI-SOA species are represented in the mechanism by SI-SOA(a) $i, e, x, n$ and SI$\operatorname{SOA}(\mathrm{g})_{i, e, x}$, for $i=1,8$ representing 8 oxidized volatility species as described by Shrivastava et al. (2008).

In addition to the 9-species VBS mechanism for POA and non-traditional SOA, we include a 4-species VBS treatment of traditional SOA (referred to as V-SOA) produced by oxidation of biogenic and traditional anthropogenic VOCs. $C^{*}$ for describing V-SOA ranges from 1 to $10^{4} \mu \mathrm{g} \mathrm{m}^{-3}$. We segregate the V-SOA species by the parent-VOC emissions sector (biogenic and traditional anthropogenic). This gives the following V-SOA species:

$\operatorname{V-SOA}(a)_{i, e, n}=$ aerosol-phase V-SOA, where $i$ is the volatility species (1-4), $e$ is either the biogenic or traditional anthropogenic emission sector, and $n$ is the size bin (1-4).

$\mathrm{V}-\mathrm{SOA}(\mathrm{g})_{i, e}=$ corresponding gas-phase V-SOA species.

The mechanism does not treat further oxidation of the VSOA gas-phase species, so separate model species for oxygen and non-oxygen component are not required for calculating O:C ratios. Instead, we assume a fixed OM:OC (mass) ratio of 1.90 and $\mathrm{O}: \mathrm{C}$ (elemental) ratio of 0.4 for V-SOA (Aiken et al., 2008).

Overall, there are 180 POA species (36 gas, 144 aerosol), 160 SI-SOA species (32 gas, 128 aerosol), and $40 \mathrm{~V}-\mathrm{SOA}$ species ( 8 gas, 32 aerosol) in the mechanism. The total SOA formed at any time within the modeling domain is the sum of SI-SOA and V-SOA after gas-particle partitioning calculations.

\subsubsection{Emissions}

An updated anthropogenic emissions inventory is used for MILAGRO 2006 from the work of Song et al. (2010). The anthropogenic emissions inventory includes traffic emissions and municipal trash burning as well as emissions from a wide range of point, and area sources. Municipal trash burning 
emissions are estimated to be comparable in magnitude to traffic emissions, but most of the trash burning sources are located outside the city. Also, municipal trash burning is expected to have similar OA spectra as fresh vehicular emissions dominated by hydrocarbon-like OA (HOA) with also some similarities with BBOA (Mohr et al., 2009). In this work, OA emissions from municipal trash burning and vehicular emissions are lumped together. BBOA represents primary biomass burning OA emissions.

Biomass burning estimates are derived from satellite remote sensing data. Emissions of gases and particles from open burning were calculated using the Fire inventory from NCAR version 1 (http://bai.acd.ucar.edu/Data/fire/). This method is based on the estimation framework described by Wiedinmyer et al. (2006). Fire counts (MODIS Data Processing System, MODAPS) were provided by the University of Maryland (Giglio et al., 2003; MODIS Rapid Response Project). Land cover was determined with the MODIS Land Cover Type product (Friedl et al., 2010) and fuel loadings from Hoezelman et al. (2004). Emission factors were taken from multiple sources (Akagi et al., 2011; Andreae and Merlet, 2001). The non-methane organic compounds were speciated to the SAPRC-99 mechanism based on species-specific emission factors and the ecosystem type in which the fire burned.

Representation of biomass burning within models is uncertain due to errors arising from calculations of plume rise, horizontal mixing of point sources and also due to the fact that several small fires may not be captured by remote sensing data (Fast et al., 2009). In this work, fire emission injection heights are treated the same as was described in Fast et al. (2009), Sect. 3.3. Emissions from fires are distributed uniformly within $\sim 300 \mathrm{~m}$ of the ground since insufficient information (e.g. fire temperature) was available to compute plume rise. Visual observations from aircraft also suggested low plume rise for these fires (R. Yokelson, personal communication, 2008). SVOC and IVOC emissions corresponding to both anthropogenic and biomass burning emissions are derived as follows:

Total SVOC emissions (organic vapors with $C^{*}$ of $0.01-$ $10^{4} \mu \mathrm{g} \mathrm{m}^{-3}$ ) are estimated as 3 times POA emissions for both anthropogenic and biomass burning emissions in Mexico City following Hodzic et al. (2010) and Tsimpidi et al. (2010). As discussed by Tsimpidi et al. (2010), POA emissions in Mexico City Metropolitan Area (MCMA) were derived for ambient conditions and reflect remaining aerosol fraction after evaporation of associated semi-volatile vapors. Since SVOC emissions were not measured in Mexico City, the ratio of SVOC to POA (assumed to be 3 in this work) is poorly constrained. In the future, it is recommended to measure and include SVOC in emission inventories to better constrain OA predictions in models.

The total SVOC emissions are then distributed among different volatility species with $C^{*}$ ranging $0.01-10^{4} \mu \mathrm{g} \mathrm{m}^{-3}$ using the mass fractions suggested by Robinson et al. (2007) with one modification. Recently, Cappa and Jimenez (2010) found that a significant fraction of POA emissions in Mexico City was globally non-volatile i.e. it would remain in particle phase under all ambient conditions. Using the default volatility distribution from Robinson et al. (2007) in the CHIMERE model, Hodzic et al. (2010) found that POA was too volatile downwind of Mexico City. In this work, using the globally non-volatile fraction suggested by Cappa and Jimenez (2010), $9 \%$ of POA emissions from biomass burning and $22 \%$ of POA emissions from anthropogenic sources are represented by the lowest volatility species with $C^{*}$ of $0.01 \mu \mathrm{g} \mathrm{m}^{-3}$ thus rendering this fraction to be non-volatile under all relevant ambient conditions in and around Mexico City. It should be noted that this assumption did not change the volatility distribution for biomass burning emissions used by Hodzic et al. (2010). Also, the volatility distribution for anthropogenic carbon used in this work is similar to biomass carbon, except the use of $23 \%$ POA emissions for the species with the $C^{*}$ of $0.01 \mu \mathrm{g} \mathrm{m}^{-3}$, in comparison to $9 \%$ used by Hodzic et al. (2010) for anthropogenic carbon. The IVOC emissions (organic vapors with $C^{*}$ of $10^{4}-10^{6} \mu \mathrm{g} \mathrm{m}{ }^{-3}$ as shown in Table 1) are estimated as 1.5 times SVOC emissions (4.5 times traditional POA emissions) for both biomass burning and anthropogenic emission sources consistent with Robinson et al. (2007). Thus, the sum of all SVOC and IVOC precursors in the inventory is 7.5 times the mass of traditional POA emissions inventory. Addition of this large pool of S/IVOC precursors to the inventory is supported by an observed gap between measured $\mathrm{OH}$ reactivity and calculated $\mathrm{OH}$ reactivity based on known VOC precursors in Mexico City (Dzepina et al., 2009). Table 2 shows the mass factors $\left(f_{i}\right)$ used to calculate S/IVOC emissions from POA emissions (converted to OC) in each category. The non-oxygen part of OM is calculated as 1.17 times the carbon part, while the oxygen part is derived from $\mathrm{O}: \mathrm{C}$ ratios, as described in Sect. 2.1.

The MEGAN (Model of Emissions of Gases and Aerosols from Nature, http://bai.acd.ucar.edu) model (Guenther et al., 2006) is used to generate biogenic emissions in the modeling domain within and around Mexico City. The 138 biogenic species from MEGAN are lumped into 3 biogenic VOC classes: isoprene (ISOP), terpenes (TERP) and sesquiterpenes (SESQ). In addition, anthropogenic VOC emissions including lumped classes corresponding to alkanes (ALK4 and ALK5), olefins (OLE1 and OLE2), and aromatics (ARO1 and ARO2) are included in the inventory corresponding to the SAPRC99 mechanism, as described by Tsimpidi et al. (2010). Isoprene and terpene emissions calculated by the NEI emissions inventory (http://mexiconei.blogspot.com/2007/ 01/national-emissions-inventory-now.html) for Mexico domain are removed to avoid double counting of biogenic emissions (already calculated by MEGAN model within the domain). This also removes the anthropogenic isoprene emissions within the modeling domain. Hodzic et al. (2009) 
Table 2. Factors $\left(f_{i}\right)$ used to calculate S/IVOC carbon emissions from POA.

\begin{tabular}{rrrr}
\hline $\begin{array}{r}C^{*} \mu \mathrm{g} \mathrm{m}^{-3} \\
\text { at } 298 \mathrm{~K}\end{array}$ & $\begin{array}{r}\text { Biomass } \\
\left(f_{i}\right)\end{array}$ & $\begin{array}{r}\text { Anthropogenic } \\
\left(f_{i}\right)\end{array}$ & $\Delta H_{\mathrm{vap} \mathrm{kJ} \mathrm{mol}^{-1}}$ \\
\hline \multicolumn{4}{c}{9 -species VBS } \\
\hline 0.01 & 0.09 & 0.23 & 112 \\
0.1 & 0.18 & 0.17 & 106 \\
1 & 0.27 & 0.26 & 100 \\
10 & 0.42 & 0.40 & 94 \\
100 & 0.54 & 0.51 & 88 \\
1000 & 0.90 & 0.86 & 76 \\
$10^{4}$ & 1.20 & 1.17 & 70 \\
$10^{5}$ & 1.50 & 1.50 & 64 \\
$10^{6}$ & 2.40 & 2.40 & \\
\hline \multicolumn{5}{c}{2 -species VBS } \\
\hline 0.01 & 1.0 & 1.0 & \\
$10^{5}$ & 6.5 & 6.5 & \\
\hline
\end{tabular}

showed that contributions of SOA formed due to oxidation of anthropogenic isoprene precursors was low $\sim 0.2 \mu \mathrm{g} \mathrm{m}^{-3}$ on an average during March 2006 at T0 site in Mexico City. As compared to Hodzic et al. (2009), this study predicts significantly lower V-SOA as discussed in the Supplement. This difference is chiefly due to lower yields for biogenic SOA precursors including isoprene in this study, as compared to parameterizations used by Hodzic et al. (2009) that were based on yields from Henze and Seinfield (2006) and Pun et al. (2006). However, V-SOA is expected to be a minor contributor to total SOA in the Mexico City region (Hodzic et al., 2010). Also, neglecting anthropogenic isoprene emissions does not affect the main objective of this paper (intercomparison of different OA formulations), as all the formulations use the same isoprene emissions.

\subsubsection{Gas phase chemistry}

All gas-phase chemistry equations leading to ozone and SOA formation are included within the Kinetic Pre-Processor (KPP) in WRF-Chem (Damian et al., 2002). The SAPRC-99 mechanism includes 211 reactions of 56 gases and 18 free radicals. This mechanism is updated to include gas-phase oxidation of various S/IVOC precursors forming SOA (A-SISOA and BB-SI-SOA for anthropogenic and biomass burning SI-SOA respectively), and SOA formed due to oxidation of VOC precursors from traditional anthropogenic and biogenic emissions (A-V-SOA and $\mathrm{B}-\mathrm{V}-\mathrm{SOA}$ respectively). The detailed treatment of OA and the inorganic MOSAIC aerosol module in WRF-Chem constitute a comprehensive representation of processes leading to organic and inorganic aerosol formation in the atmosphere. In the present version, the gas- particle partitioning of SOA species is treated as an instantaneous equilibrium process, while the gas-particle mass transfer of inorganic species is treated as a particle size-dependent dynamic process. Also, the organic and inorganic species are not allowed to interact with each other in the particle phase state and water uptake calculations. These assumptions will be relaxed in the future as experimentally derived parameterizations of complex physicochemical interactions between organic and inorganic species as well as dynamic condensation, evaporation, and reactive uptake of organic gases are implemented in the MOSAIC aerosol module.

\section{SI-SOA formation}

Observations suggest continued SOA production as pollutants leave the Mexico City basin during low biomass burning periods (DeCarlo et al., 2008; Kleinman et al., 2008). Thus, multi-generational SOA chemistry and/or SOA formation from longer lived precursors are consistent with ambient observations. SI-SOA formation from multi-generational gas-phase oxidation of S/IVOC precursors are calculated using oxidation parameters proposed by Robinson et al. (2007) with one modification. The mass of parent SVOC or IVOC species is assumed to increase by $15 \%$ for each generation of oxidation to account for added oxygen mass or functionalization. This is equivalent to assuming that 2 atoms of oxygen are added to an equivalent $\mathrm{C}_{15} \mathrm{H}_{32}$ precursor per generation of oxidation. In comparison, Robinson et al. (2007) assumed an addition of $7.5 \%$ mass due to added oxygen. The oxidation mechanism proposed by Robinson et al. (2007) was not designed to predict the oxidation state of $\mathrm{OA}$ in the atmosphere. Use of $7.5 \%$ added oxygen mass has been shown to severely under-predict the O:C ratios in the atmosphere (Hodzic et al., 2010). Jimenez et al. (2009) suggested that 1 to 3 oxygen atoms could be added per generation of oxidation. Grieshop et al. (2009) used $40 \%$ increase in mass due to addition of oxygen per generation of oxidation for wood smoke. Thus, the addition of 2 oxygen atoms is a fairly conservative assumption improving $\mathrm{O}: \mathrm{C}$ ratio predictions as compared to 1 oxygen atom added by Robinson et al. (2007). An $\mathrm{OH}$ reaction rate constant of $4 \times 10^{-11} \mathrm{~cm}^{3}$ molecule ${ }^{-1} \mathrm{~s}^{-1}$ is assumed for all SVOC and IVOC species.

The equations governing oxidation of S/IVOC precursors are written within the KPP module of WRF-Chem as follows:

$$
\begin{aligned}
& \mathrm{POA}(\mathrm{g})_{i, e, c}+\mathrm{OH} \rightarrow \mathrm{SI}-\mathrm{SOA}(\mathrm{g})_{i-1, e, c} \\
&+ 0.15 \mathrm{SI}-\mathrm{SOA}(\mathrm{g})_{i-1, e, o} \\
& \mathrm{POA}(\mathrm{g})_{i, e, o}+\mathrm{OH} \rightarrow \mathrm{SI}-\mathrm{SOA}(\mathrm{g})_{i-1, e, o}+\mathrm{OH} \\
& \mathrm{SI}-\mathrm{SOA}(\mathrm{g})_{i, e, c}+\mathrm{OH} \rightarrow \mathrm{SI}-\mathrm{SOA}(\mathrm{g})_{i-1, e, c}+0.15 \mathrm{SI} \\
&-\mathrm{SOA}(\mathrm{g})_{i-1, e, o}
\end{aligned}
$$


$\mathrm{SI}-\mathrm{SOA}(\mathrm{g})_{i, e, o}+\mathrm{OH} \rightarrow \mathrm{SI}-\mathrm{SOA}(\mathrm{g})_{i-1, e, o}+\mathrm{OH}$

where, $i$ denotes any given volatility species except the lowest volatility, $i-1$ denotes the species with $C^{*}$ equal to $i / 10$, $e$ denotes the source type, and subscripts $c$ and $o$ represent the non-oxygen and oxygen parts respectively of given species. As shown by equations (1) and (3), oxidation of non-oxygen part of SI-SOA precursor $i$ results in formation of non-oxygen and oxygen parts $(15 \%$ by mass for 2 oxygen atoms added) of SI-SOA with successive lower volatility $i-1$. Since molecular weights of all VBS species are assumed as $250 \mathrm{~g} \mathrm{~mole}^{-1}$ mass yields are same as molar yields, so 0.15 is used as oxygen yield per oxidation step within KPP. Equations (2) and (4) account for movement of oxygen part of each precursor to lower volatility. Thus at any time, both non-oxygen and oxygen parts of any given species move to successively lower volatility species due to oxidation, satisfying mass conservation. The lowest volatility species $\left(C^{*}\right.$ equal to $0.01 \mu \mathrm{g} \mathrm{m}^{-3}$ ), was assumed to be non-reactive, neglecting fragmentation reactions, following Robinson et al. (2007). In Eqs. (2) and (4), OH was added to both sides of the equations to make sure that $\mathrm{OH}$ loss is not double counted by oxidation of non-oxygen and oxygen parts of the same species.

\section{V-SOA formation}

SOA formation from biogenic and traditional anthropogenic VOCs (V-SOA) is represented using fixed yields of these species using a 4-product VBS following Tsimpidi et al. (2010). For alkane, olefin, isoprene, terpene and sesquiterpene SOA species, mass yields are similar to Tsimpidi et al. (2010). For aromatic species yields from Hildebrandt et al. (2009) are implemented. Aging of VOCs in the gas-phase could be represented by the following equation:

$\mathrm{VOC}(\mathrm{g})_{i}+\mathrm{OH} \rightarrow \sum_{i=1}^{n} a_{i} \mathrm{~V}-\mathrm{SOA}(\mathrm{g})_{i-1}$

$a_{i}=a_{i, \operatorname{high}} B+a_{i, \mathrm{low}}(1-B)$

where $i$ is the volatility species, $a_{i}$ is the overall $\mathrm{NO}_{\mathrm{x}}$ depen-

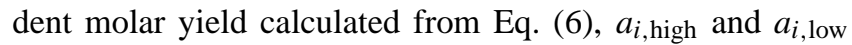
are the molar yields under high and low $\mathrm{NO}_{\mathrm{x}}$ conditions respectively, $B$ is the $\mathrm{NO}_{\mathrm{x}}$ branching ratio as defined by Lane et al. (2008), and V-SOA $(\mathrm{g})_{i}$ is the gas phase V-SOA precursor concentration. The reaction rates of various VOC species with the $\mathrm{OH}$ radicals in Eq. (5) are already present within the SAPRC-99 mechanism, as a part of gas-phase chemistry, with the exception of sesquiterpenes. In this work, it is assumed that sesquiterpenes have the same $\mathrm{OH}$ reaction rate as the terpene species in SAPRC-99. While sesquiterpenes may react much faster with $\mathrm{OH}$ radicals as compared to terpenes, their emissions are significantly lower. Sesquiterpene concentrations within the modeling domain are atleast an order of magnitude lower than terpenes. Formation of
$\mathrm{V}-\mathrm{SOA}(\mathrm{a})_{i}$ is represented by gas-particle partitioning of $\mathrm{V}$ $\operatorname{SOA}(\mathrm{g})_{i}$ defined by absorptive partitioning theory as discussed by Donahue et al. (2006). However, in contrast to Tsimpidi et al. (2010), no further aging of the $\mathrm{V}-\mathrm{SOA}(\mathrm{g})_{i}$ species is implemented in WRF-Chem as including it leads to larger regional over-prediction of SOA (Dzepina et al., 2011). Aging parameterizations based on smog chamber measurements are very uncertain as they try to predict SOA formation over longer time-scales (photochemical ages) than so far have been accessible in chambers ( $\mathrm{Ng}$ et al., 2010). Smog chamber measurements need to be carried out to much longer time-scales (over several days) and $\mathrm{OH}$ exposures to quantify and parameterize multi-generational V-SOA formation from both biogenic and traditional anthropogenic precursors.

In this work, V-SOA yields are $\mathrm{NO}_{\mathrm{x}}$ dependent as described by Tsimpidi et al. (2010). Table S1 in the Supplement lists mass yields of various V-SOA precursors represented by the 4-product VBS species V-SOA $(\mathrm{g})_{i}$. Molar yields are required as the SAPRC-99 mechanism lists equations and reaction rates in molecular units within the Kinetic Pre-Processor (KPP) in WRF-Chem. Mass yields listed in Table S1 are converted to molar yields by multiplying them with the ratio of molecular weights of $\mathrm{V}-\mathrm{SOA}(\mathrm{g})_{i}$ species (assumed to be $250 \mathrm{~g} \mathrm{~mole}^{-1}$ ) and the corresponding $\mathrm{VOC}(\mathrm{g})$ precursors taken from the CAMx User's guide for SAPRC 1999 mechanism (CAMx vs 5.10 User's guide, 2009). The assumed enthalpy of vaporization $\Delta H_{\text {vap }}$ for the $\mathrm{V}-\mathrm{SOA}(\mathrm{g})_{i}$ species are equal to same-volatility $\operatorname{SI-SOA}(\mathrm{g})_{i}$ species shown in Table 1.

\subsection{Condensed 2-species OA mechanism}

As discussed earlier, the addition of a large number of species represents a huge computational burden in terms of advection alone. Development of a condensed 2-species mechanism is attractive for computational efficiency in large-scale global simulations. In this section, assumptions and parameterizations for development of the condensed 2-species mechanism within WRF-Chem are discussed.

The condensed mechanism represents POA by two volatility species with $C^{*}$ values (at $298 \mathrm{~K}$ and $1 \mathrm{~atm}$ ) of $10^{-2}$ and $10^{5} \mu \mathrm{g} \mathrm{m}^{-3}$ respectively. Separate POA species are used to represent the two emissions sectors and the oxygen and nonoxygen $(\mathrm{C}, \mathrm{H}, \mathrm{N})$ components of each species as described in Sect. 2.1 above. This gives the following:

- $\operatorname{POA}(\mathrm{a})_{i, e, x, n}=$ aerosol-phase POA, where $i$ is the volatility species, $e$ is either the biomass or anthropogenic emission sector, $x$ is either the oxygen or nonoxygen component, and $n$ is the size bin (1-4) as described in Sect. 2.1.

- $\operatorname{POA}(\mathrm{g})_{i, e, x}=$ corresponding gas-phase POA species. The gas-phase $\operatorname{POA}(\mathrm{g})_{i=2, e, x}$ species $\left(C^{*}\right.$ of $\left.10^{5} \mu \mathrm{g} \mathrm{m}^{-3}\right)$ reacts with $\mathrm{OH}$ to produce $\operatorname{SI}-\operatorname{SOA}(\mathrm{a})_{i=1, e, x, n}$ and 
$\operatorname{SI-SOA}(\mathrm{g})_{i=1, e, x}\left(C^{*}\right.$ of $\left.10^{-2} \mu \mathrm{g} \mathrm{m}^{-3}\right)$. Note that POA (a) $i=2, e, x$ would almost entirely remain in the gas phase under most atmospheric conditions due to its high volatility.

In addition to the 2-species VBS mechanism for POA and non-traditional SI-SOA, we include a 1-species treatment of traditional SOA (referred to as V-SOA) produced by oxidation of biogenic and traditional anthropogenic VOCs. VSOA $C^{*}$ is assumed to be equal to $1 \mu \mathrm{g} \mathrm{m}^{-3}$ corresponding to the lowest volatility species in 4-product VBS for VSOA in Sect. 2.1.2. We segregate the V-SOA species by the parent-VOC emissions sector (biogenic and traditional anthropogenic) giving $\mathrm{V}-\mathrm{SOA}(\mathrm{a})_{i=1, e, n}$ and $\mathrm{V}-\mathrm{SOA}(\mathrm{g})_{i=1, e}$ as described in Sect. 2.1.2.

In the condensed mechanism, there are 40 POA species ( 8 gas, 32 aerosol), 20 SI-SOA species (4 gas, 16 aerosol), and $10 \mathrm{~V}$-SOA species (2 gas, 8 aerosol) in the mechanism.

\subsubsection{S/IVOC emissions}

The condensed 2-species approach represents POA and SOA as the first volatility species with $C^{*}$ of $10^{-2} \mu \mathrm{g} \mathrm{m}{ }^{-3}$. This approach assumes that both POA and SOA in the model are non-volatile under most atmospherically relevant conditions. POA emissions are assumed to be $1 / 3 \mathrm{rd}$ of SVOC emissions in the 9-species VBS approach discussed in Sect. 2.1.1., allowing 2/3rd of SVOC emissions to have already evaporated relative to 9-species VBS approach, thus implicitly accounting for gas-particle partitioning. IVOC emissions (are 6.5 times POA and include 2/3rd of SVOC emissions) are represented as the 2nd IVOC species with of $C^{*}$ of $10^{5} \mu \mathrm{g} \mathrm{m}^{-3}$. The 2nd species represents all gas phase S/IVOC emissions within the modeling domain. Hence $C^{*}$ for this species is chosen to be in the IVOC range to ensure all material remains in the gas phase under most atmospheric conditions. The total SVOC and IVOC emissions in the 2-species VBS approach are equal to the 9 -species VBS. Table 2 shows the factors $\left(f_{i}\right)$ used to calculate S/IVOC emissions from POA. As discussed earlier POA emissions are divided by 1.57 and 1.25 for biomass burning and anthropogenic emissions respectively, to convert OM to OC prior to application of factors $f_{i}$ in Table 2 . The enthalpy of vaporization $\Delta \mathrm{H}_{\text {vap }}$ is assumed to be $83 \mathrm{~kJ} \mathrm{~mol}^{-1}$ as in Pye and Seinfield (2010), but the model is not very sensitive to $\Delta \mathrm{H}_{\mathrm{vap}}$ for the two volatility species used in the condensed mechanism as the material represented by either species is firmly in one phase and far from the region where substantial fractions are in both phases.

The SAPRC-99 gas-phase chemistry leading to ozone formation in condensed 2-species VBS is exactly the same as detailed 9-species VBS. However, reactions and SOA yield leading to SI-SOA and V-SOA formation are different and are discussed in the following section.

\subsubsection{SOA formation}

\section{SI-SOA}

SI-SOA is formed by gas-phase oxidation of S/IVOC vapors represented by the 2 nd volatility species $\left(\mathrm{C}_{\mathrm{sat}}\right.$ of $\left.10^{5} \mu \mathrm{g} \mathrm{m}^{-3}\right)$, with each generation of oxidation moving material to the 1st volatility species, thus representing 7 orders of magnitude reduction in volatility. For a given reaction rate and S/IVOC emissions, this mechanism will be much faster in producing SOA as compared to the 9-species VBS. In order to align SOA predictions from the 2 species VBS to the 9-species VBS, the reaction rate with $\mathrm{OH}$ radical is reduced by a factor of 7 as compared to 9-species VBS approach (OH reaction rate of $0.57 \times 10^{-11}$ molecule $\mathrm{cm}^{-3} \mathrm{~s}^{-1}$ ). An addition of $50 \%$ oxygen mass is also assumed for the one generation of oxidation (instead of $15 \%$ in the 9-species VBS approach) following the discussions by Pye and Seinfield (2010).

Equations (1)-(4) are repeated within KPP for the 2species VBS approach, but these equations are only written once resulting in oxidation of S/IVOC of species 2 on the left hand side to form SI-SOA represented by species 1 on the right hand side. The large addition of oxygen and reduction of volatility in one oxidation step is not meant to represent a physical process, but rather to parameterize the average effect of the more complex real processes, as the 7 times slower $\mathrm{OH}$ reaction rate makes up for the large changes, bringing predictions of SI-SOA in the 2-species VBS closer to 9-species VBS as shown later.

\section{V-SOA}

$\mathrm{V}$-SOA formation is represented using fixed 1-product yields of these species. In the 4-product basis set for V-SOA as described by Tsimpidi et al. (2010), the lowest volatility species has a $C^{*}$ of $1 \mu \mathrm{g} \mathrm{m}^{-3}$. For consistency, the volatility of 1-product V-SOA is assumed to have a $C^{*}$ of $1 \mu \mathrm{g} \mathrm{m} \mathrm{m}^{-3}$ at $298 \mathrm{~K}$. The $\mathrm{NO}_{\mathrm{x}}$ dependent 1-product mass yields for traditional anthropogenic and biogenic V-SOA precursors are given in Table S2 in the Supplement. The SOA yields for olefin species are chosen to be equal to the yields corresponding to species with $C^{*}$ of $1 \mu \mathrm{g} \mathrm{m}^{-3}$ in the 4-product VBS from Tsimpidi et al. (2010). For alkane species, since SOA yields corresponding to species with $C^{*}$ of $1 \mu \mathrm{g} \mathrm{m}{ }^{-3}$ are zero in Tsimpidi et al. (2010), yields from the next higher volatility species $\left(C^{*}\right.$ of $\left.10 \mu \mathrm{g} \mathrm{m}^{-3}\right)$ are assigned to the lowest volatility species. Yields for ARO1 and $\mathrm{ARO} 2$ are assumed to be equal to toluene and $m$-xylene SOA yields respectively following Ng et al. (2007b). These yields are chosen to be higher than respective ARO1 and $\mathrm{ARO} 2$ yields corresponding to $C^{*}$ of $1 \mu \mathrm{g} \mathrm{m}^{-3}$ in Table 3. Yields for TERP and SESQ species are assumed to be equal to $\alpha$-pinene and aromadendrene respectively ( $\mathrm{Ng}$ et al., 2007a). All yields are chosen at lowest $\Delta \mathrm{M}_{0}$ values measured during the experiments which are closer to ambient SOA concentrations. 
Table 3. Statistics comparing AMS PMF factors to corresponding WRF-Chem species predictions for the three modeling cases discussed in this study at urban T0 site and suburban T1 site.

\begin{tabular}{l|rrr|rrr|rrr}
\hline & \multicolumn{2}{|c|}{ HOA $\left(\mu \mathrm{g} \mathrm{m}^{-3}\right)$} & OOA $\left(\mu \mathrm{g} \mathrm{m}^{-3}\right)$ & \multicolumn{2}{|c}{ BBOA $\left(\mu \mathrm{g} \mathrm{m}^{-3}\right)$} \\
\hline T0 Cases & 1 & 2 & 3 & 1 & 2 & 3 & 1 & 2 & 3 \\
\hline Mean obs. & & 5.81 & & & 7.63 & & 2.58 & \\
${ }^{*}$ Bias $\left(\mu \mathrm{g} \mathrm{m}^{-3}\right)$ & -2.97 & 0.50 & -0.30 & -2.60 & -0.86 & -0.95 & -2.13 & -2.09 & -1.95 \\
$* *$ Correlation & 0.50 & 0.50 & 0.50 & 0.23 & 0.19 & 0.42 & 0.21 & 0.21 & 0.19 \\
\hline T1 Cases & 1 & 2 & 3 & 1 & 2 & 3 & 1 & 2 & 3 \\
\hline Mean obs. & & 1.23 & & & 4.43 & & & 1.44 & \\
$*$ Bias $\left(\mu \mathrm{g} \mathrm{m}^{-3}\right)$ & -0.39 & 0.61 & 0.64 & 0.33 & 2.09 & 1.91 & -1.11 & -1.08 & -0.91 \\
$* *$ Correlation & 0.27 & 0.27 & 0.26 & 0.15 & 0.11 & 0.26 & 0.27 & 0.28 & 0.26 \\
\hline
\end{tabular}

${ }^{*}$ Bias $\left(\mu \mathrm{g} \mathrm{m}^{-3}\right)=\frac{1}{N} \sum_{i}\left(M_{i}-O_{i}\right)$ where $N$ is the number of samples, $O_{i}$ are the AMS PMF factors, and $M_{i}$ are WRF-Chem predictions. ** Correlation represents pearson correlation coefficients between AMS PMF factors and WRF-Chem predictions. WRF-Chem data were interpolated in time to AMS data for calculation of statistics. The AMS data were available for 10-31 March 2006 at T0 site and 12-30 March 2006 at T1 site.

The traditional A-V-SOA and B-V-SOA predicted from the 4-species formulation shown in Table S1 were found to be similar to the 1-species formulation shown in Table S2. All SOA formation in this work is assumed to result from photochemical reaction with $\mathrm{OH}$ radicals. Reactions with $\mathrm{O}_{3}$ and $\mathrm{NO}_{3}$ radicals may also be important for SOA formation under certain conditions (e.g. Capouet et al., 2008), and they will be incorporated into WRF-Chem in the future.

\subsection{Dry and wet deposition}

Dry deposition for all gas-phase SOA precursor species is calculated using the resistance model of Wesely (1989) assuming a Henry's law constant of $2700 \mathrm{M} \mathrm{atm}^{-1}$ which is used for species such as cresol and condensable organic gases as documented in CAMx user's guide (Environ, 2009). Dry deposition of OA is treated within MOSAIC similar to inorganic aerosols. Wet deposition is neglected in present work. Cloud-aerosol interactions, including wet removal, for all aerosols are not accounted for because the first two weeks of the MILAGRO campaign were mostly cloud free (Fast et al., 2007). Periods of afternoon convection and scattered precipitation did occur during the last week of the field campaign, but previous simulations using WRF-Chem by Fast et al. (2009) found that the amount of aerosols removed by the wet deposition during that period was relatively small. Also, the computational burden of handling the cloud processes would be excessive in the 9-species VBS formulation due to the need to transport both interstitial and cloud-borne copies of each aerosol species. This would almost double the cost of the simulation. The condensed 2-species VBS formulation developed in this work is more suitable for complex cloud-aerosol interactions in WRF-Chem.

\subsection{Modeling runs}

A nested grid configuration with an outer grid using $12 \times 12 \mathrm{~km}^{2}$ grid spacing and an inner grid using $3 \times 3 \mathrm{~km}^{2}$ grid spacing is used to model the Mexico City region. For both detailed and condensed mechanisms, all OA species including freshly emitted POA and SOA are assumed to form an ideal solution. The total OA within the modeling domain is calculated as the sum of POA, SOA, and a small amount $\left(0.1-0.3 \mu \mathrm{g} \mathrm{m}^{-3}\right)$ of background OA coming from boundary conditions obtained from MOZART global simulations of trace gases and aerosols (Emmons et al., 2010). Initial and boundary condition for all newly added VBS OA species is assumed to be zero. Three modeling cases were carried out. The 9-species VBS was run for two anthropogenic S/IVOC emissions cases: (1) default emissions from 2006 inventory (2) twice the amount of default S/IVOC emissions as compared to (1). S/IVOC emissions from biomass burning are assumed to be identical in both cases. The reasoning behind these runs is that default emissions from (1) using the 2006 MCMA inventory significantly under-predicted HOA as compared to AMS measurements. Using twice the amount of S/IVOC emissions allows us to study the sensitivity of HOA and SOA to anthropogenic emissions. In the third model Case, the condensed 2-species VBS mechanism was run with S/IVOC emissions equal to Case (2) above. Thus comparison of Cases (2) and (3) enables us to evaluate the condensed mechanism against the detailed 9-species VBS mechanism. The condensed mechanism predicts the same information as the 9-species VBS including source-resolved POA and SOA mass concentrations, and evolution of O:C ratios using the 4-species sectional representation for aerosols. 
(a) Case 1

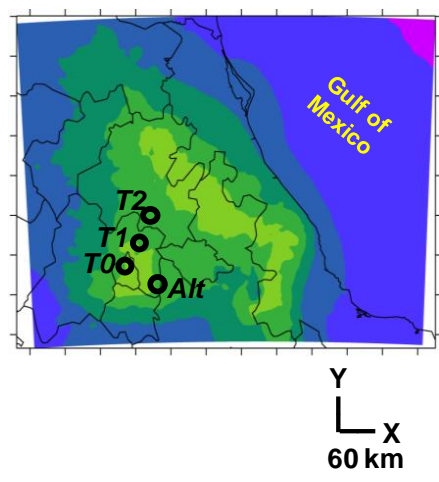

(b) Case 2
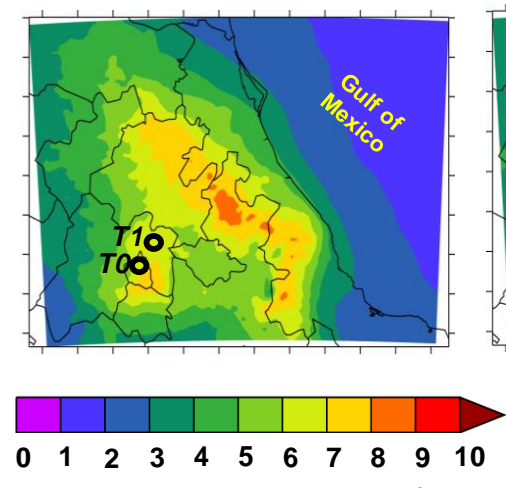

(c) Case 3

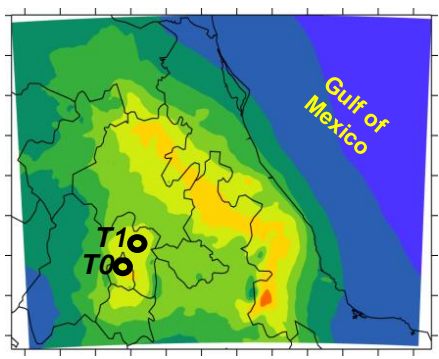

Fig. 1. Spatial distribution of 24-day average $\mathrm{PM}_{2.5}$ SOA concentrations $\left(\mu \mathrm{g} \mathrm{m}^{-3}\right)$ over Mexico City basin as predicted by 3 modeling Cases discussed in the text. Also indicated are locations of T0 site within city, T1 and T2 sites at the edge of the city, and the Altzomoni (Alt) site. Case 1 represents 9 species VBS with default emissions, while Case 2 and Case 3 represent 9 species and 2 species VBS respectively with twice anthropogenic S/IVOC emissions, as discussed in the text.

For comparison with measurements, model predictions are spatially and temporally interpolated to the location of the measurement for both aircraft flights and ground site data using the Aerosol Modeling Testbed Toolkit developed for WRF (Fast et al., 2011). Ground measurements are compared with the lowest level in the model $(\Delta z \sim 25 \mathrm{~m})$. Comparisons between measurements and model predictions are done at local ambient conditions of pressure and temperature for both ground sites and aircraft flights. Also, all WRFChem results are extracted for the inner grid using $3 \times 3 \mathrm{~km}^{2}$ grid spacing. Spatial maps shown in the present study (for e.g. Fig. 1) represent the part of modeling domain where the nested grid configuration was used. The larger $12 \times 12 \mathrm{~km}^{2}$ grid spacing modeling domain is shown in previous studies e.g. Fast et al. (2007). In WRF-Chem, the predicted OA in particle size bins $1-3(0.039-2.5 \mu \mathrm{m}$ dry diameter $)$ is compared to AMS measurements. Fraction of mass in the third size bin (between $0.625 \mu \mathrm{m}$ and $2.5 \mu \mathrm{m}$ ) was often less than $15 \%$ of total $\mathrm{PM}_{2.5}$ OA mass.

\section{Results and discussion}

In this section, the three modeling cases are evaluated with highly time-resolved AMS measurements at two surface sites (T0 and T1) and several aircraft flights (8 G-1 flight tracks and 2 C-130 flight tracks) within and around Mexico City. Predicted organic aerosols are evaluated with respect to mass of total OA, HOA, OOA and BBOA, and $\mathrm{O}: \mathrm{C}$ ratio measurements. The rigorous evaluation with the comprehensive measurements in Mexico City region is essential to evaluate the emissions inventory and the OA mechanism, and also establish the utility of the simpler 2-species VBS mechanism in predicting OA concentrations for future regional and global simulations.

\subsection{Spatial distributions of SOA}

Figure 1 shows spatial distributions of 24-day average total SOA surface concentrations during 6-30 March, 2006 as predicted by the three modeling cases. SOA predictions from 9-species VBS and condensed 2-species VBS cases (Cases 2 and 3) are very similar throughout the modeling domain. In comparison, Case 1 with half the anthropogenic S/IVOC emissions predicts lower SOA formation as expected, due to smaller amounts of S/IVOC precursors as compared to the other two cases.

Figure 2 shows the 24-day average contributions of various SOA components as a percentage of OA for Case 2. As shown in Fig. 2a, A-SI-SOA contributes $20-30 \%$ to OA at T0 site located within Mexico City. As the S/IVOC precursors move downwind and undergo multiple generations of oxidation chemistry, A-SI-SOA is dominant and contributes $50-70 \%$ to OA. BB-SI-SOA forms the second major component contributing $10-30 \%$ to OA as shown in Fig. $2 \mathrm{~b}$. The upper-right corner of Fig. 2b shows dominant BB-SISOA contribution in a part of Gulf of Mexico, but 24-day average absolute concentrations of BB-SI-SOA ranged 0.6$0.8 \mu \mathrm{g} \mathrm{m}^{-3}$ in that region, and were less than $1 \mu \mathrm{g} \mathrm{m}^{-3}$ over the entire Gulf of Mexico. In comparison, higher BB-SISOA concentrations ranging $1.7-2.0 \mu \mathrm{g} \mathrm{m}^{-3}$ are observed over land and areas surrounding Mexico City (at T0 and T1 sites not shown here). Figure $2 \mathrm{c}$ and d shows that both traditional SOA components (B-V-SOA and A-V-SOA) contribute a much lower fraction $(2-5 \%)$ to total OA. B-VSOA is higher in areas where biogenic emissions are higher, whereas A-V-SOA is highest within the city and decreases downwind. The decrease in A-V-SOA is in contrast to the increase in A-SI-SOA downwind from Mexico City. This decrease is due to the fact that in the present formulation, 
(a) A-SI-SOA / Total OA

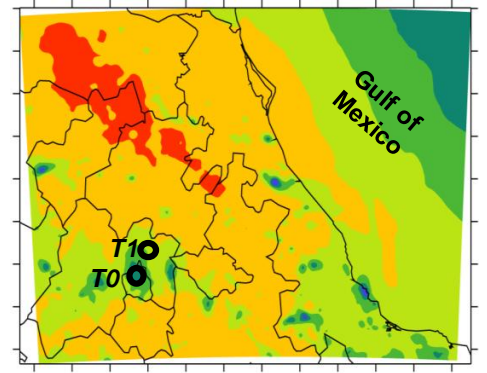

(c) B-V-SOA / Total OA

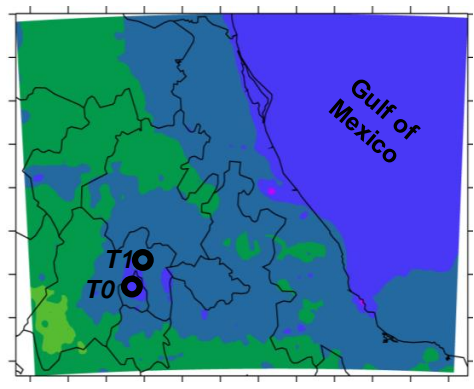

(b) BB-SI-SOA / Total OA

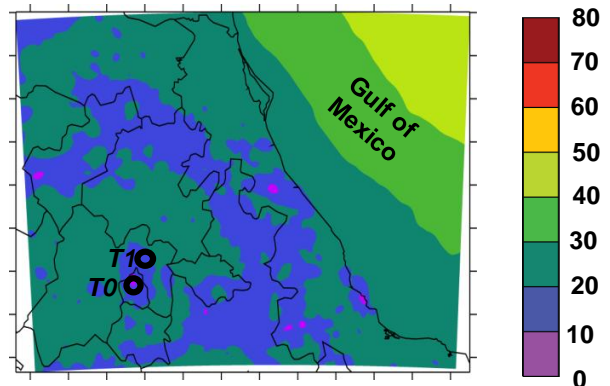

(d) A-V-SOA / Total OA

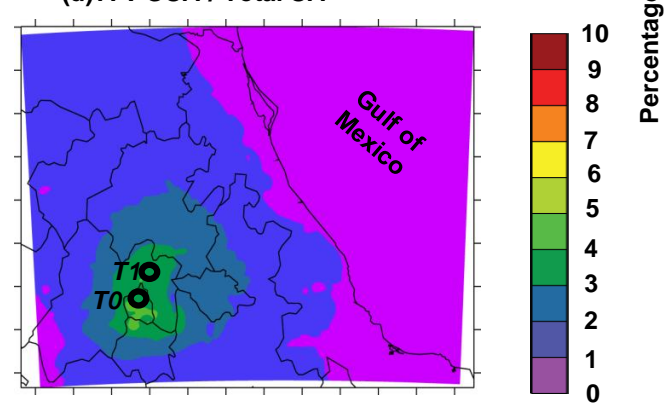

Fig. 2. Spatial distribution of 24-day average $\mathrm{PM}_{2.5}$ SI-SOA components (a) anthropogenic A-SI-SOA (b) biomass burning BB-SI-SOA (c) biogenic B-V-SOA (d) traditional anthropogenic A-V-SOA as a percentage of total OA over Mexico City basin as predicted by Case 2 (9-species VBS with twice default anthropogenic S/IVOC emissions).

A-V-SOA is formed only by first generation products of VSOA precursors emitted close to the city and partially evaporates with dilution downwind of the city (Dzepina et al., 2011), while A-SI-SOA formation continues downwind due to multiple generations of chemistry.

\subsection{Evaluation of OA components at $\mathrm{TO}$ site}

The T0 site is situated within the center of Mexico City, representing an area dominated by urban emissions. In WRFChem oxidation by $\mathrm{OH}$ radicals leads to SOA formation, so accurate representation of $\mathrm{OH}$ radical concentrations is necessary. As shown in the Supplement Fig. S7, WRF-Chem under-predicts $\mathrm{OH}$ concentration peak at day-time by a factor of 2 as compared to observations at the T0 site (Dusanter et al., 2009), but reproduces the timing of the $\mathrm{OH}$ peak. Also, WRF-Chem predicts near-zero $\mathrm{OH}$ concentrations during night-time, while measurements show higher concentrations. But effects of low $\mathrm{OH}$ concentrations observed during night-time (order of magnitude lower than day-time) on SOA formation is expected to be small.

Model $\sum \mathrm{POA}(\mathrm{a})_{i}$, antrhopogenic, $x, n$ is compared to PMF HOA factor, $\sum \mathrm{SI}-\mathrm{SOA}(\mathrm{a})_{i, e, x, n}+\sum \mathrm{V}-\mathrm{SOA}(\mathrm{a})_{i, e, x, n}$ is com-

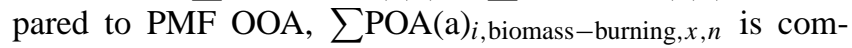
pared to PMF BBOA, and total simulated $\mathrm{PM}_{2.5}$ OA is compared to measured total OA from PMF. Figure 3 compares observed and simulated HOA and OOA at the T0 site.

\subsubsection{HOA}

Models reproduce observed diurnal variations of HOA peaking in the early morning rush hour period due to traffic emissions as shown in Fig. 3a. However, all 3 modeling cases under-predict the magnitude of observed peak in HOA. Figure $3 \mathrm{c}$ shows that on an average across all days, the default emissions (Case 1) under-predicts morning HOA peak by a factor of 3, implying problems with the 2006 emissions inventory. Case 2 (9-species VBS) and Case 3 (2-species VBS) with twice the anthropogenic S/IVOC emissions better represent traffic emissions. Table 3 shows bias and correlation coefficients of HOA, OOA and BBOA comparing WRF-Chem predictions to AMS PMF data. Table 3 shows a higher negative HOA bias of $-2.97 \mu \mathrm{g} \mathrm{m}^{-3}$ for Case 1 compared to other two cases. Also, since the spatial and temporal variation of POA emissions is similar for all three cases, the Pearson correlation coefficient for HOA is same for the three cases. HOA peak from 9-species VBS is $35 \%$ higher than 2-species VBS during early morning. The difference is related to the volatility distribution of SVOC emissions, as the 9-species VBS allows dynamic gas-particle partitioning using a globally non-volatile fraction of $22 \%$ as described earlier, while the 2-species VBS assumes that a constant fraction (onethird) of the SVOC emissions are HOA at all times. This is also reflected in small positive HOA bias of $0.5 \mu \mathrm{g} \mathrm{m}^{-3}$ for Case 2, as compared to a small negative bias of $-0.3 \mu \mathrm{g} \mathrm{m}^{-3}$ for Case 3 when comparing against the AMS data (Table 3 ). 

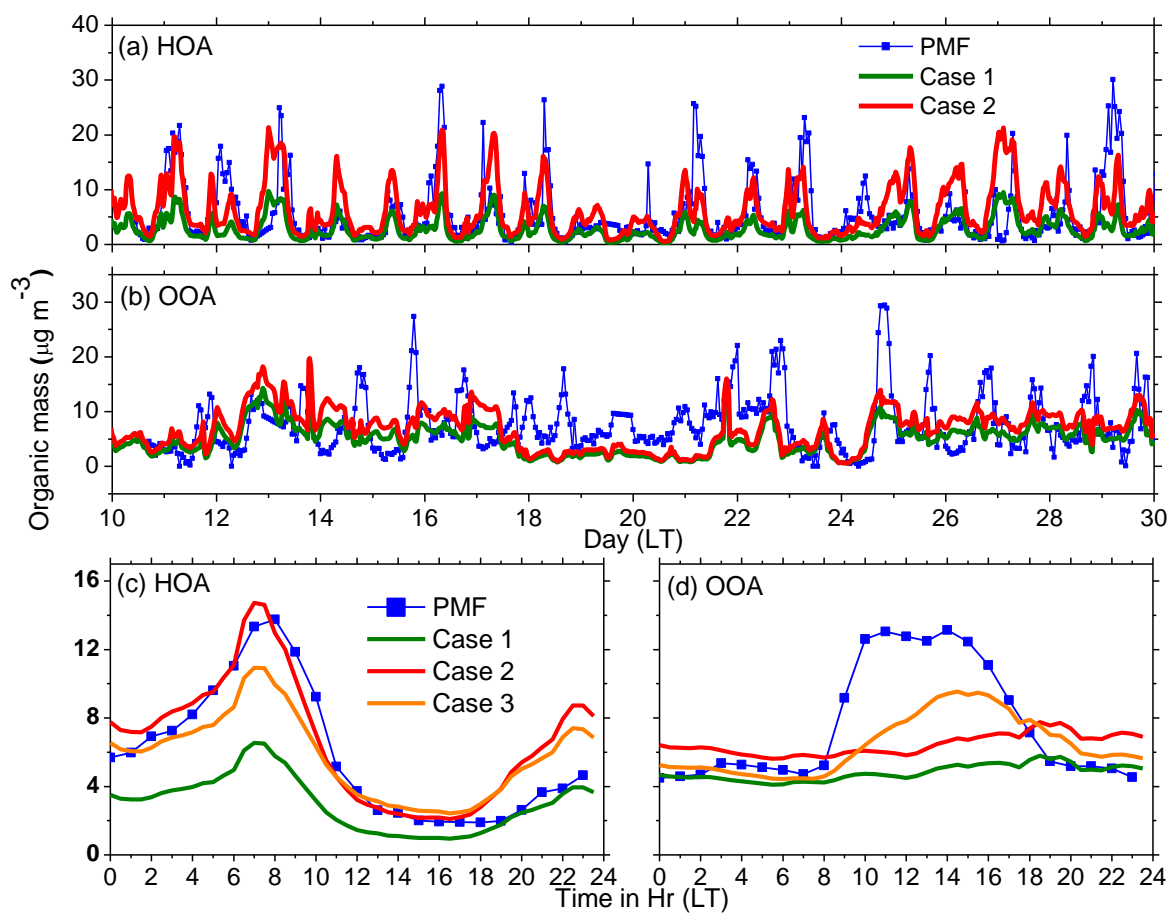

Fig. 3. Observed and simulated OA components at the T0 site within Mexico City. (a) HOA time series (b) OOA time series (c) HOA diurnal average (d) OOA diurnal average. Case 3 is not shown in panels (a) and (b) as it is very similar to Case 2.

\subsubsection{OOA}

Figure $3 \mathrm{~b}$ shows that after 18 March, OOA is under-predicted by all modeling cases. The diurnal average plot in Fig. 3d shows that PMF OOA increases by a factor of 3 during the afternoon as compared to night-time, due to photochemistry. But, Case 1 and Case 2 predict almost constant SOA concentrations throughout the day due to compensating effects of dilution by growth of boundary layer and photochemistry as day progresses. In addition, Table 3 shows significantly higher OOA negative bias $\left(-2.6 \mu \mathrm{g} \mathrm{m}^{-3}\right)$ for Case $1 \mathrm{com}-$ pared to the other two cases. Among the 3 modeling cases, the 2-species VBS (Case 3) is closest to PMF OOA, predicting two times higher afternoon peak as compared to morning as shown in Fig. 3d. Also, Table 3 shows significantly higher correlation of SOA predictions from Case $3(0.42)$ as compared to the other two cases ( 0.23 and 0.19 respectively). The differences between 9-species and 2-species VBS are due to volatility distribution of SOA, as the 2-species VBS causes all SOA formed to be almost non-volatile at ambient conditions $\left(C^{*}\right.$ of $10^{-2} \mu \mathrm{g} \mathrm{m}^{-3}$ ), while the 9-species VBS allows evaporation of SOA with dilution as the boundary layer grows. Higher correlation of 2-species VBS SOA predictions with AMS PMF OOA implies that SOA may be less volatile as compared to the volatility distribution in the 9-species VBS mechanism, as shown by Cappa and Jimenez (2010) and Dzepina et al. (2009, 2011). Consistent with this, Vaden et al. (2011) recently showed that both laboratory generated and ambient SOA particles do not evaporate at room temperature for hours even under extremely dilute vapor-free conditions. Also, within the existing modeling framework, the under-predictions of HOA and OOA using default emissions (Case 1) is caused due to lower emissions. Dzepina et al. (2009) in a box modeling study derived HOA and S/IVOC from observations, rather than the emissions inventory, and observed better closure between modeled SOA and OOA observations. Aiken et al. (2009) concluded that total primary PM (not the same as POA) was underestimated by about a factor of 4 with respect to the 2006 emissions inventory, therefore it is possible that an underestimation of urban POA emissions remains in Case 2, leading to the observed discrepancy. Also, the 2006 biomass burning emissions inventory for Mexico City of Wiedynmier et al. (2006) under-predicts BBOA as compared to PMF BBOA. Table 3 shows consistently high BBOA negative biases, on the order of $-2 \mu \mathrm{g} \mathrm{m}^{-3}$, for all three modeling cases. Missing SOA from biomass burning precursors may also be responsible for model-measurement differences in OOA, although the BBOA under-prediction is stronger during the early morning (Fig. 4c), and the low levels of the biomass burning tracer acetonitrile at $\mathrm{T} 0$ during afternoons (Aiken et al., 2010) make this possibility less likely. 

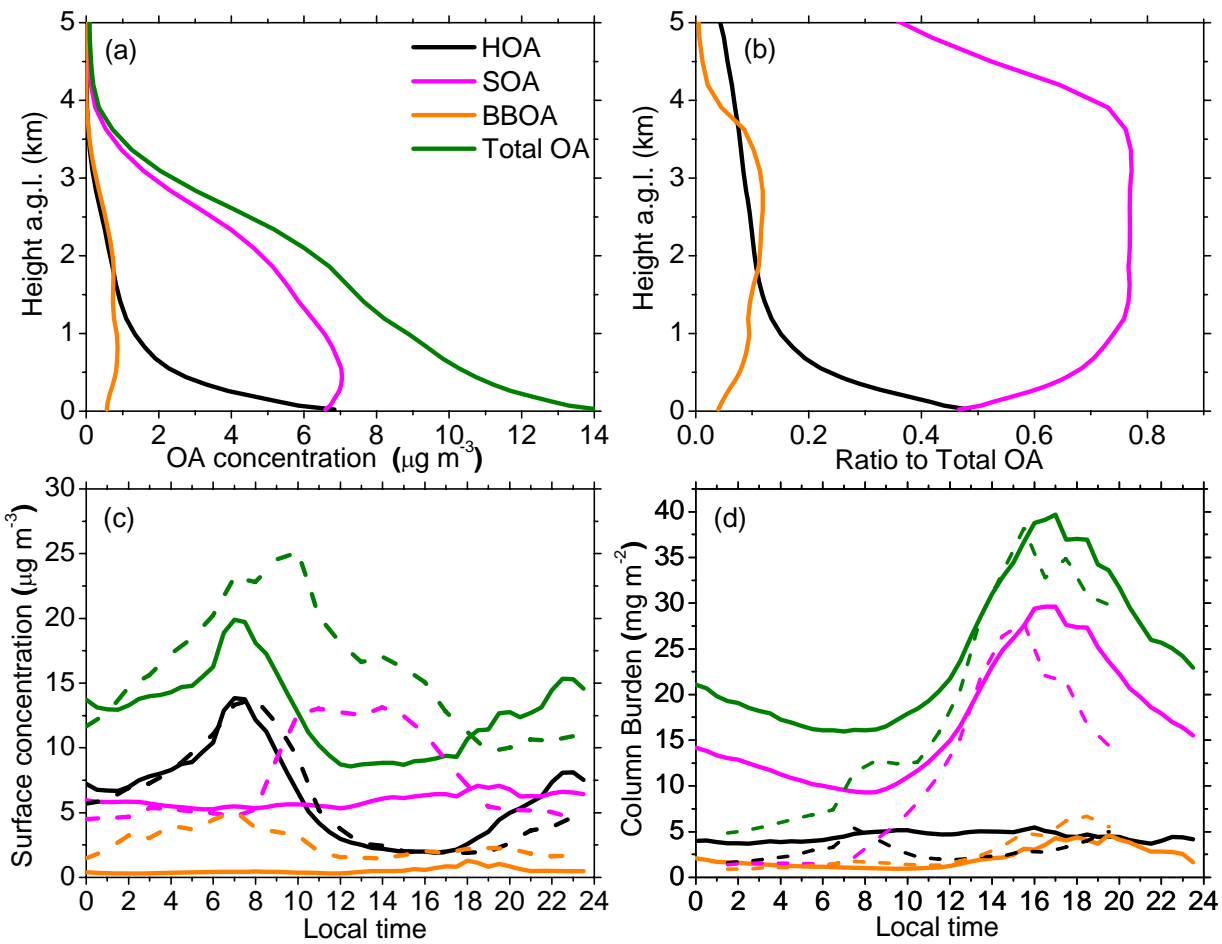

Fig. 4. 24 day averages over 6-30 March 2006 at T0 site predicted by Case 2 within Mexico City for (a) Variation of OA concentration $\left(\mu \mathrm{g} \mathrm{m}^{-3}\right.$ ) with height above ground level (a.g.1.) (b) Ratio of HOA, SOA and BBOA from (a) with respect to total OA (c) Diurnal variation of surface concentrations ( $25 \mathrm{~m}$ a.g.l.) of OA components. Solid lines show WRF-Chem Case 2 simulations, while dashed lines show AMS PMF data (d) Diurnal variation of total column burden $\left(\mathrm{mg} \mathrm{m}^{-2}\right)$ of OA components. Solid lines show Case 2 WRF-Chem simulations, while dashed lines show column burdens estimated by Aiken et al. (2010) over 10-31 March 2006 at T0 site for comparison.

\subsubsection{Vertical profile, surface concentration and column burden}

In addition to surface concentrations, it is also useful to look at vertical concentration profiles and total column integrated burdens of various OA components. Surface concentrations of pollutants are monitored for their health impacts, while vertical concentration profile and total column burden are important for climate effects.

Figure 4a shows the vertical distribution of HOA, SOA, BBOA and total OA concentrations, while Fig. 4b shows ratio of OA components to total OA with height above ground level (a.g.1.) at the T0 site. HOA concentrations are maximum at the surface ( $48 \%$ of total OA as shown in Fig. 4b) and decrease with increasing AGL. SOA concentration is comparable to HOA at the surface, but decreases much slower as compared to HOA at higher levels. Figure $4 \mathrm{~b}$ shows that ratio of $\mathrm{SOA} /$ total OA increases from 0.5 near the surface to 0.75 at $1-4 \mathrm{~km}$ a.g.l. height. Continued photochemical oxidation of SOA precursors in the atmosphere causes SOA to be dominant component of OA above the surface even over the highly urbanized T0 site as shown in Fig. 4b. Thus model predictions imply that SOA is the most important component of OA in the atmosphere affecting both human health and climate. The ubiquity and dominance of SOA in the atmosphere is also implied by PMF analysis of AMS measurements (Zhang et al., 2007). The fractional importance of BBOA increases with height from $4 \%$ near the surface to $12 \%$ at $3 \mathrm{~km}$ a.g.l. as shown in Fig. $4 \mathrm{~b}$. The vertical distribution of BBOA emissions in WRF-Chem is based on the fire emission locations in the hills and mountains surrounding Mexico City, as well as mixing of smoke in the boundary layer before it is transported into Mexico City. Previous aircraft measurements have also seen increasing BBOA with height in Mexico City (Aiken et al., 2010; Crounse et al., 2009).

Figure $4 \mathrm{~d}$ shows diurnal variation of total column integrated burden $\left(\mathrm{mg} \mathrm{m}^{-2}\right)$ of OA components in the atmosphere. Solid lines in the figure represent results from Case 2 in present study, while dashed lines represent estimations from previous work by Aiken et al. (2010). The SOA burden decreases during night-time, but increases due to photochemistry in the day peaking at 16:00-17:00 LT. The magnitude and timing of daytime peak in SOA burden is comparable to the previous estimates by Aiken et al. (2010). Aiken et al. (2010) calculated the column burdens by multiplying surface concentrations with boundary layer depths assuming constant concentration across depth of boundary layer, 
but neglected species present above boundary layer in the morning. In the present study, column burden is calculated by integrating vertical concentration profile of OA components adding species present within and above the boundary layer till the top of modeling domain as predicted by WRFChem. SOA estimated by Aiken et al. (2010) in the nighttime and early morning till 08:00 LT are factor of 4-9 lower than present study as shown in Fig. 4d. There is good agreement for the middle of the day when the convective boundary layer is deep, but the column burden is strongly underestimated using the method of Aiken et al. (2010) in the nighttime and early morning when the boundary layer is shallow. This underestimation points to a very important conclusion that there is often substantial OA in the residual layer above the boundary layer in the night-time and early morning, and it should not be neglected in model calculations.

It is also instructive to compare diurnal variations of total column burden vs. surface concentration of various OA components as shown in Fig. $4 \mathrm{c}$ and d. Surface concentration shown in Fig. 4c changes due to evolution of boundary layer as the day progresses, but the total column integrated burden (shown in Fig. 4d) is not influenced by vertical dilution due to changing boundary layer. Model surface SOA concentrations do not indicate significant diurnal variation due to opposing effects of dilution and photochemistry, but total SOA burden shows a strong diurnal variation due to photochemistry. Also HOA surface concentration peaks at 07:00 LT, but column burden of HOA is nearly constant throughout the day. BBOA surface concentrations and column burden both show similar diurnal variations with peaks at 18:00 LT due to relatively uniform vertical distribution of BBOA shown in Fig. 4a and b. Total OA surface concentrations and column burden follow corresponding diurnal variations of SOA.

\subsubsection{O:C ratio}

$\mathrm{O}: \mathrm{C}$ ratios provide another measure to verify the performance of SOA treatments, supplementing evaluations using OA mass and its components. The evolution of the carbon and oxygen parts of SI-SOA are explicitly tracked in WRFChem, making it possible to calculate temporal and spatial variations in elemental $\mathrm{O}: \mathrm{C}$ ratios in the aerosol phase. In Fig. 5, we evaluate modeled O:C ratio predictions in terms of 20-day diurnal variations at the $\mathrm{T} 0$ site, time averaged spatial variation across the modeling domain and along two C-130 flight transects in the atmosphere. Figure 5a compares measured and simulated temporal variation of $\mathrm{O}: \mathrm{C}$ ratios at the T0 site, while Fig. 5b looks at 24-day average spatial variation of elemental O:C ratios predicted by Case 2. In this study, two oxygen atoms are added per generation of oxidation of S/IVOC precursors as discussed earlier. Figure 5a shows that all three modeling cases reproduce the temporal variations of $\mathrm{O}: \mathrm{C}$ ratios, but the magnitude is under-predicted at the T0 site. Case 1 is closest to AMS measurements predicting higher elemental O:C ratios as compared to Case 2 and 3. O:C ratios decrease as fresh reduced primary organic emissions are added every hour in the model, but increase as photochemistry causes SOA formation with addition of oxygen. Case 1 has half of the fresh reduced anthropogenic emissions as compared to Case 2, resulting in higher O:C ratios.

Case 3 (2-species VBS) predicts very similar O:C ratios as Case 2 at T0 site as shown in Fig. 5a. The agreement in O:C ratios between Case 2 and Case 3 over the city is very interesting. Case 2 represents 9 -species VBS with $15 \%$ added oxygen mass per generation of oxidation, while Case 3 represent 2 -species VBS with $50 \%$ added oxygen and 7 times slower chemistry as compared to Case 2 . Figure $5 b$ shows that predicted 24-day average O:C ratios varies spatially ranging from a high of 0.3 at $\mathrm{T} 0$ site increasing to 0.6 further downwind, and could be as high as 0.7 over the Gulf of Mexico representing highly oxygenated organic material. In comparison, Hodzic et al. (2010) and Dzepina et al. (2011) predicted much smaller O:C ratios ranging $0.14-0.24$ over the Mexico City domain using the ROB approach adding one oxygen atom per generation of oxidation following Robinson et al. (2007). These studies better predicted the O:C ratios both within the city and downwind using the GRI approach in which the added oxygen mass was $40 \%$ and the chemistry was 2 times slower than in our simulation.

Figure $5 \mathrm{c}$ and d compare AMS O:C ratios to WRF-Chem simulations along C-130 flight tracks on 10 March (a high biomass burning day) and 29 March (a low biomass burning day), respectively. This comparison along the flight transects allows a more comprehensive evaluation of $\mathrm{O}: \mathrm{C}$ ratios as compared to just ground site locations. A portion of the C130 flight transects were located further downwind of Mexico City as discussed later. All 3 model Cases reproduce variations in measured AMS O:C ratios on 10 March reasonably well; but simulations under-predict peaks in O:C ratios, specially at downwind locations. The two large peaks in O:C ratios predicted by Case 1 and Case 2 in Fig. $5 c$ are during lowest OA predictions events chiefly dominated by SOA. On March 29, WRF-Chem simulations consistently underpredict $\mathrm{O}: \mathrm{C}$ ratios as compared to measurements (shown in Fig. 5d). Most of the simulated values vary around 0.5 , while AMS measured O:C ratios as high as 0.8 downwind of Mexico City on this day. It is important to note that the 2-species VBS (Case 3) predicts lower O:C ratios than 9-species VBS (Case 2) over downwind locations on this day; however the differences between these cases are less than $25 \%$. All 3 modeling cases show very similar temporal variations in O:C ratios, which is expected since temporal variations in emissions, deposition, meteorology, and chemistry are similar within WRF-Chem for all runs.

Results from both this study and previous studies show a strong sensitivity of $\mathrm{O}: \mathrm{C}$ ratios to the assumed oxygen added per generation of oxidation and point towards a need for additional experimental validation. Also fragmentation reactions which could cause an increase in O:C ratios (Kroll et 


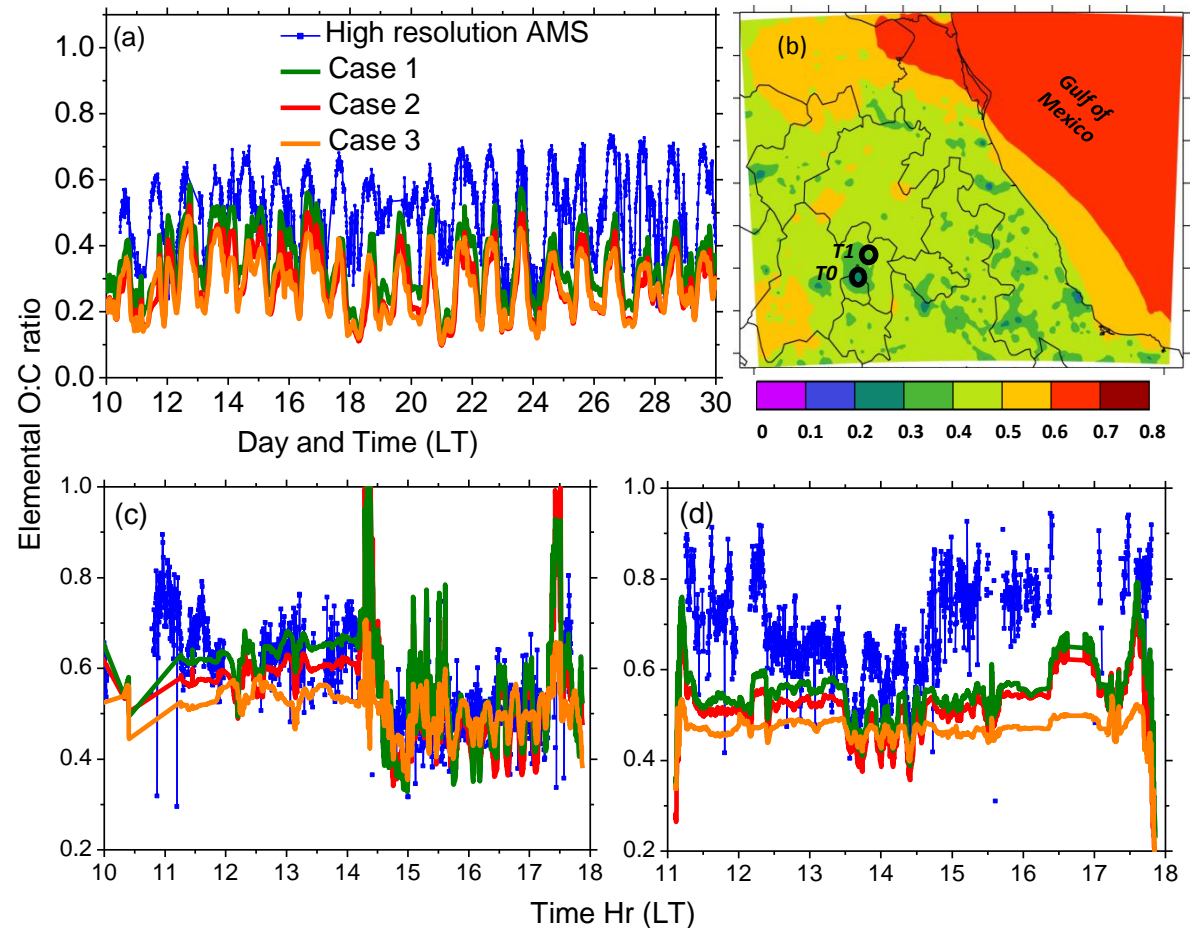

Fig. 5. Elemental O:C ratios over Mexico City region. (a) Time series of AMS and model results at T0 site for 10-30 March, (b) 24-day average spatial distribution at surface level for Case 2 (c) AMS and model results along C-130 flight track of 10 March morning (d) results along C130 flight track on morning of 29 March.

al., 2009) need to be included in future parameterizations. Improving emission estimates for e.g. increasing biomass burning emissions would also help to increase O:C ratio predictions bringing them closer to measurements. Accurate predictions of $\mathrm{O}: \mathrm{C}$ ratios are important to better understand the resulting effects on direct and indirect radiative forcing of climate by relating aerosol optical properties and $\mathrm{CCN}$ activation as function of chemical processing of $\mathrm{OA}$ in the atmosphere (Jimenez et al., 2009).

\subsection{Evaluation of $\mathrm{OA}$ components at $\mathrm{T} 1$ site}

The T1 site is located at the northern edge of the city. As discussed in Fast et al. (2009), the present WRF-Chem setup uses $3 \times 3 \mathrm{~km}^{2}$ grid spacing which may not be enough to represent the strong spatial gradients of emissions in this region. Figure 6a-d compare average diurnal variations of AMS total OA, HOA, OOA and BBOA with corresponding WRFChem predictions. As shown in Fig. 6b, Case 1 with default emissions under-predicts the early morning HOA peak by a factor of 2, while the other two modeling cases reproduce both magnitude and timing of the early morning HOA peak. Figure $6 \mathrm{c}$ shows that PMF OOA peaks during late afternoon due to photochemical production of SOA. The timing of the late afternoon PMF OOA peak is best reproduced by Case 3, but Case 3 over-predicts magnitude of this peak by $40 \%$. In comparison, both Case 1 and Case 2 show SOA peaking later in the day as compared to PMF OOA. As shown in Table 3, while OOA bias is lowest for Case 1, Case 3 shows the highest correlation with PMF OOA at T1 site. Some of this over-prediction in SOA may also be due to uncertainties in chemistry parameterization producing too much SI-SOA downwind of the city center. Figure $6 \mathrm{~d}$ shows two peaks in AMS PMF BBOA during early morning and late afternoon hours respectively. All model predictions clearly show significantly lower BBOA and do not capture the timing and magnitude of measured PMF BBOA, pointing to limitations in biomass burning emission inventory. Table 3 shows consistent negative biases in BBOA for all three modeling cases.

Overall, the default emissions inventory (Case 1) underpredicts surface level HOA at both $\mathrm{T} 0$ and $\mathrm{T} 1$ sites. Also, Table 3 shows significantly lower correlation of predicted and observed HOA at the T1 site as compared to the T0 site $(0.27$ for $\mathrm{T} 1$ vs. 0.50 for $\mathrm{T} 0)$, suggesting that the spatial and temporal distribution of POA emissions needs to be revised in the 2006 emissions inventory. The diurnal variation of OOA is not well captured by all three modeling Cases at both T0 and T1 sites. Also, both 9-species and 2-species VBS schemes show significantly greater bias and lower correlations for OOA as compared to $\mathrm{HOA}$ at $\mathrm{T} 0$ and $\mathrm{T} 1$ sites as shown in Table 3. But, Case 3 with 2-species VBS predicts OOA concentrations better at both $\mathrm{T} 0$ and $\mathrm{T} 1$ sites as compared to other two modeling cases, reflected in significantly 
higher correlation coefficients of Case 3 predictions with AMS OOA. Since SI-SOA contributes major fraction of SOA within the modeling domain, these results suggest that both volatility distribution and chemistry parameterizations of SISOA are poorly constrained. Consistent with trends in HOA and OOA, total OA is under-predicted by Case 1, at both T1 and T0 (not shown) sites as compared to observations.

\subsection{Evaluation of OA components aloft}

AMS measurements aloft are available from G-1 (Kleinman et al., 2008) and C-130 (DeCarlo et al., 2008) aircraft flight transects. The two aircrafts made several transects on different days flying above the center of Mexico City and downwind. This high-time resolution AMS data is valuable to study time evolution and growth of organic aerosols as they move from city to further downwind locations.

Figures 7 and 8 compare WRF-Chem outputs to highly time resolved AMS data for OA components along the C-130 transect on 10 March and the G-1 transect on 15 March, respectively. On 10 March, MODIS detected several large fires within $60 \mathrm{~km}$ of Mexico City, thus it was a high biomassburning day. March 15 was a day with relatively low biomass burning. Both WRF-Chem and AMS data are averaged to 1 min time intervals to reduce high-frequency variability and ease visual comparison.

\subsubsection{C-130 flight on 10 March}

On the morning of 10 March, 2006, the C-130 aircraft encountered a large number of biomass burning fires as detected by MODIS fire counts (Fast et al., 2009) as it flew from the Gulf of Mexico towards Mexico City. The aircraft sampled several downwind locations between Mexico City and Veracruz at 11:00-14:00 LT. Figure 7a shows that there may be small transport and dilution errors close to 12:3013:00 LT shown by difference in measured and simulated CO concentrations. When the aircraft flew close to the city over T0 and T1 sites (14:30-16:00 LT), Fig. 7a shows that CO is over-predicted somewhat by WRF-Chem as compared to observations; however, the temporal variations look consistent. The C-130 then flew back to Veracruz late in the afternoon. The high temporal variability in $\mathrm{CO}$ and $\mathrm{OA}$ emissions is caused by the aircraft flying within and outside the boundary layer.

Figure $7 \mathrm{~b}$ shows that variations in total $\mathrm{OA}$ over city region are reasonably simulated by all WRF-Chem modeling cases. WRF-Chem slightly under-predicts total OA over the city as compared to AMS data. However, when the aircraft flew over downwind locations earlier during the day, WRF-Chem overpredicts total OA by more than a factor of 2 as compared to AMS measurements.

Figure 7c shows that HOA is under-predicted by all modeling cases over the city. Also, at downwind locations, OOA is over-predicted by upto a factor of 5 by all three modeling cases as shown in Fig. 7d. The overestimation in OOA points to missing processes such as fragmentation reaction which are not included in this study. Figure 7e shows that BBOA is consistently under-predicted both over the city and downwind locations pointing to problems in the biomass burning emissions inventory.

Figure $7 \mathrm{f}$ quantifies different SOA source-contributions in this study along the flight track using Case 2. These include V-SOA from traditional anthropogenic and biogenic precursors (A-V-SOA and B-V-SOA), and SI-SOA from S/IVOC precursor emissions related to anthropogenic and biomass burning emissions (A-SI-SOA and BB-SI-SOA respectively). Both over the city and at downwind locations ASI-SOA and BB-SI-SOA are equally important. Traditional A-V-SOA and B-V-SOA contributes a much smaller fraction to SOA both over city and downwind locations, and biomass burning and anthropogenic emissions (predominantly traffic emissions) are the two major SOA precursor sources within and around the Mexico City region. Total simulated OA in Fig. $7 \mathrm{~b}$ looks better as compared to individual derived OA components due to compensating errors from simulated $\mathrm{HOA}$ and $\mathrm{BBOA}$ that are too low and OOA that is too high.

\subsubsection{G-1 flight on 15 March}

Another example is shown in terms of G-1 flight transects on the morning of 15 March in Fig. 8. This was a low biomass burning day as compared to 10 March. As shown in Fig. 8a, spatial variations of predicted $\mathrm{CO}$ are qualitatively similar to observations. The largest scatter in observed and simulated $\mathrm{CO}$ occurs over the city due to errors in timing and location of simulated plume (Fast et al., 2009).

Figure $8 \mathrm{~b}$ shows that variations in total OA are reasonably simulated by WRF-Chem over the city and nearby downwind locations. OA is over-predicted at farther downwind locations mainly due to over-prediction in OOA. As shown in Fig. 8c, simulated HOA is under-predicted over the city as compared to AMS HOA (during 11:00-11:30 LT). Case 1 predicts lower HOA as compared to other two cases due to lower anthropogenic S/IVOC emissions as discussed earlier. The consistent under-prediction in HOA suggests possible errors in SVOC emissions or volatility distribution of emissions, e.g. a potentially higher fraction of SVOC emissions being non-volatile than assumed in the current model.

Between 10:00-10:30 LT and 11:30-12:30 LT the aircraft flew downwind over T1 and between Mexico City and Veracruz farther downwind. Figure 8d shows that OOA is overpredicted both over the city and downwind by all modeling cases, with much higher over-prediction downwind as compared to over city. Figure 8e also shows that BBOA is under-predicted on this day too by all modeling cases. Figure $8 \mathrm{f}$ shows SOA source-contributions using Case 2 along the flight transect. Over the city, A-SI-SOA is dominant contributor to SOA. At farther downwind locations, BB-SISOA starts playing a more important role consistent with 

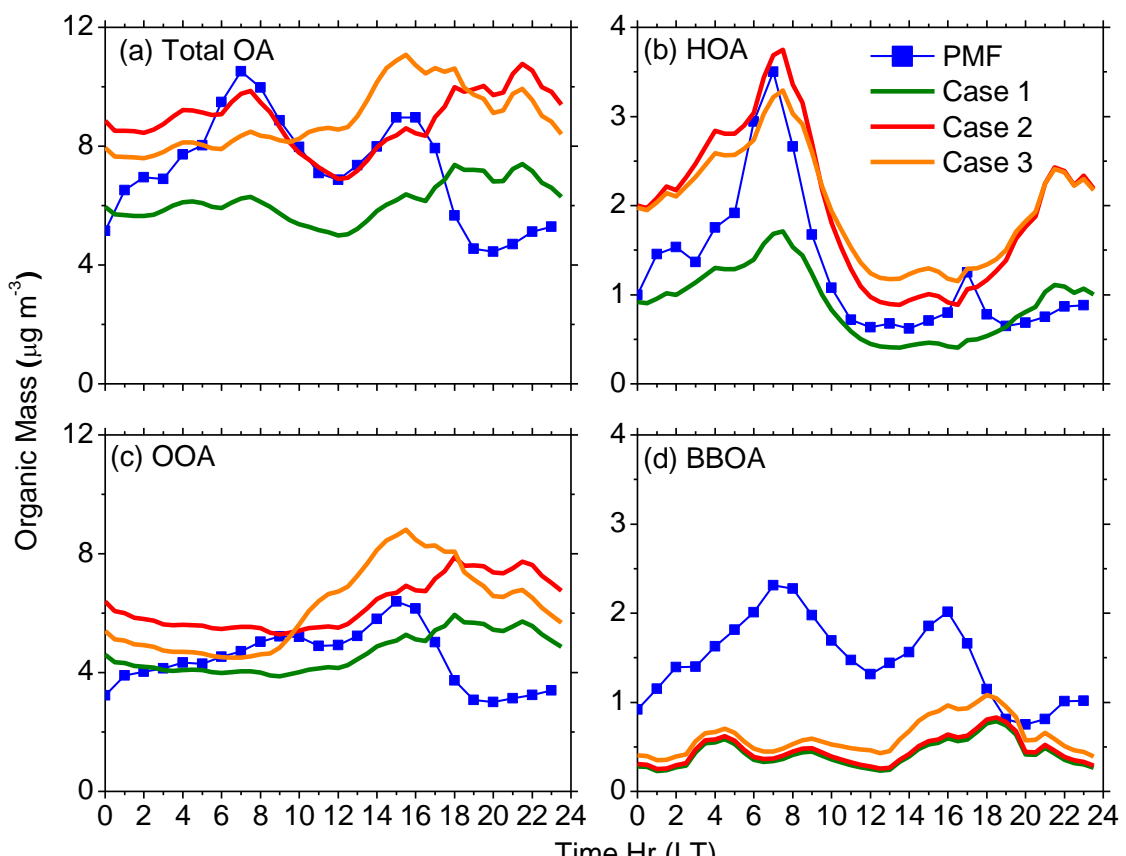

Fig. 6. Average diurnal observed and simulated OA components at the T1 site within Mexico City for (a) Total OA (b) HOA (c) OOA (d) BBOA.

conclusions from C-130 flight transect shown in Fig. 7f. As expected, traditional A-V-SOA is higher over the city where anthropogenic emission sources are higher as compared to downwind locations. Also, both traditional A-V-SOA and B-V-SOA precursors contribute relatively low SOA mass as compared to S/IVOC precursors from anthropogenic and biomass burning emissions.

\subsubsection{Model-measurement comparisons across several flight tracks}

So far we have looked at 2 flight transects in detail. Figure 9 compares WRF-Chem predictions to AMS PMF data for eight G-1 and two C-130 flights. Variations in both WRFChem predictions and AMS data are represented by box plots showing percentiles. Figure 9 shows that WRF-Chem predictions of HOA are lower than that derived from PMF, while WRF-Chem over-predicts SOA on most flight days, consistent with all discussions so far. PMF HOA also shows significantly greater variability on any given day as compared to predictions. Part of the variability in PMF HOA may arise due to the fact that PMF of unit resolution data used for the G-1 aircraft, has difficulty separating contributions of HOA and BBOA (Aiken et al., 2009). C-130 data utilize high-resolution AMS data, which is much better able to separate HOA and BBOA components. But as discussed earlier, significant spatial and temporal variation of emissions also causes higher variability in PMF HOA which is not captured by 2006 MCMA emissions inventory used in this work.
Almost an opposite trend is seen for OOA in Fig. 9b. On most days, the model over-predicts SOA as compared to corresponding PMF OOA. In addition, the model predictions show greater variability as compared to PMF observations. The greatest predicted variability in the simulations is seen for the C-130 flight on 10 March. 10 March was a high biomass burning day with several large fires within $60 \mathrm{~km}$ of Mexico City. Biomass burning contributions to SI-SOA on this day were similar to anthropogenic SI-SOA contributions (as shown in Fig. 7f). Figure 9c shows that predicted BBOA across most flight tracks (especially evident on high biomass burning days, such as 10 March) is too low, pointing to significant uncertainties and missing biomass burning smoke emissions in the inventory used here. Most importantly, Fig. 9 shows that the magnitude and variability of HOA, SOA and BBOA predicted by 9-species VBS and 2species VBS mechanisms are very similar. This comprehensive evaluation using aircraft measurements over both city and downwind locations provides evidence of the utility of the condensed 2-species VBS mechanism to represent OA in climate models. WRF-Chem under-predicts total OA across most G-1 flight transects as shown in Fig. 9d, consistent with under-prediction of HOA and BBOA over the city. Also, WRF-Chem over-predicts total OA at farther downwind locations as shown by the two C-130 flights on 10 and 29 March respectively, due to significant over-prediction of SOA downwind. 

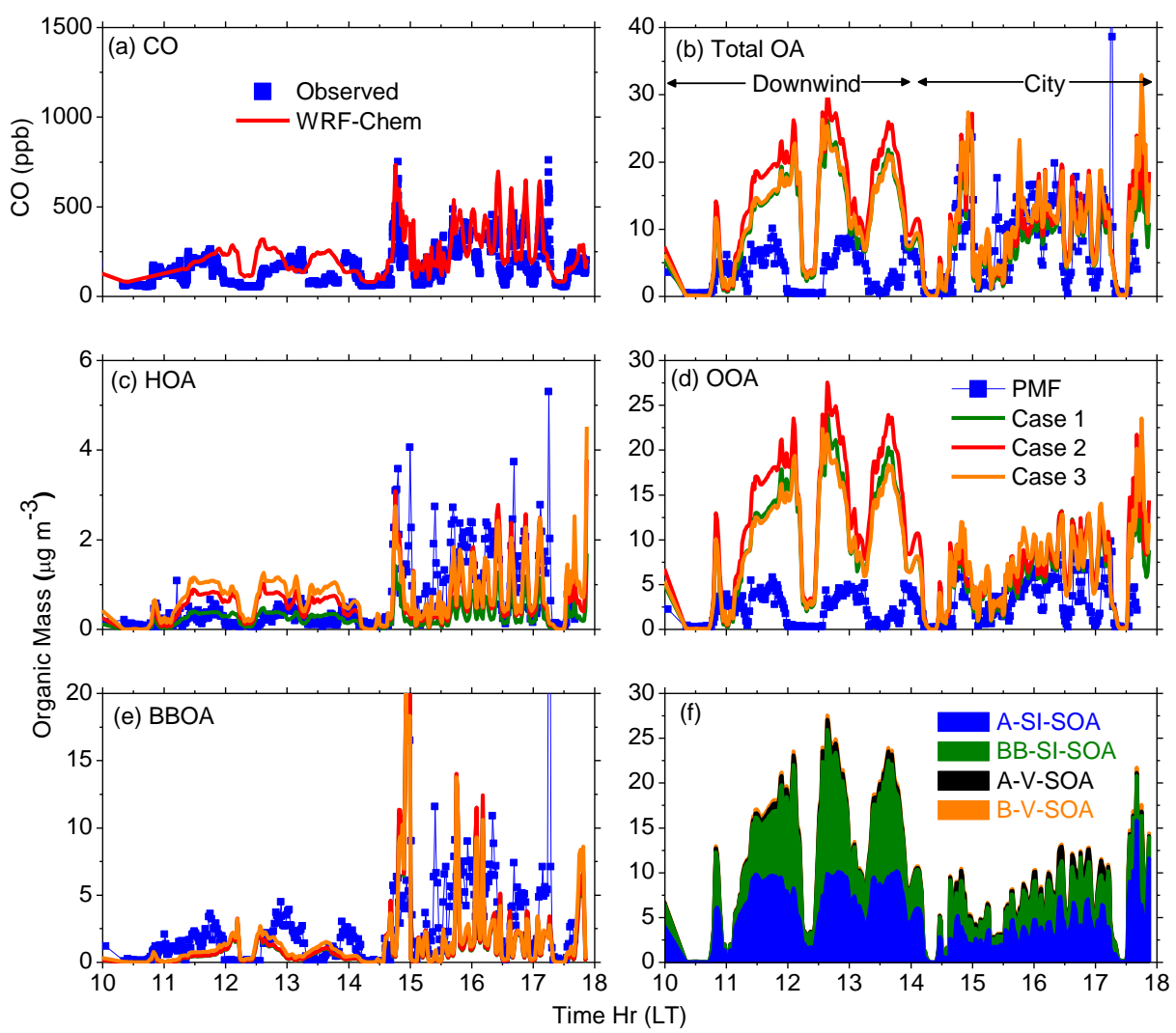

Fig. 7. Comparing WRF-Chem predictions to measurements (a) CO mixing ratios, and (b) total OA, (c) HOA, (d) OOA and (e) BBOA versus corresponding Positive matrix factorization (PMF) factors. (f) Various SOA components predicted by WRF-Chem Case 2 simulations along flight transect of C-130 on 10th of March as discussed in text. Case 1, Case 2 and Case 3 are different modeling Cases as discussed in the text. PMF data are averaged to 1 min time intervals to reduce visual clutter. In (f), blue and green denote the sum of semi-volatile and intermediate volatility SOA from anthropogenic and biomass burning sources, respectively, and black and orange denote SOA from traditional anthropogenic and biogenic sources, respectively.

Section S3.0 in the supporting online information compares predictions from WRF-Chem using 9-species VBS (Case 2) against CHIMERE model predictions described by Hodzic et al. (2010). The main differences include the following: (1) WRF-Chem uses online meteorology and CHIMERE uses offline meteorology, as discussed earlier, (2) the CHIMERE model includes the wet deposition of aerosols, whereas WRF-Chem does not, and (3) the emissions of POA are based on two different inventories. Differences in coupling of processes between online and offline air quality modeling, as discussed by Grell et al. (2004), likely contribute to some of the differences in the chemical fields between WRF-Chem and CHIMERE. Additional differences in gas-phase chemistry, dry deposition, and implementation of VBS between the two models are discussed in Sect. S3.0. Section S3.0 shows that predictions of WRFChem and CHIMERE are comparable at the T0 site, while WRF-Chem predicts on average $50 \%$ higher (and closer to observed) SOA than CHIMERE at the T1 site.

\section{Discussion}

The VBS approach formulated by Robinson et al. (2007) is useful to represent varying gas-particle partitioning and multi-generational photochemical aging of a complex mixture of thousands of organic species in air-quality models. In this work, it is shown that HOA is better simulated by the VBS approach as compared to OOA. Model simulation with the all 3 Cases show significantly high bias and low correlations with AMS PMF OOA at the T0 and T1 sites (Table 3). In addition the VBS approach significantly overpredicts OOA downwind of city as shown by flight transects. These results show limitations in representation of processes contributing to formation and evolution of secondary organic aerosols in models. As shown in this study and several recent studies using this approach for Mexico City (Dzepina et al., 2009, 2011; Hodzic et al., 2010; Shrivastava et al., 2008; Tsimpidi et al., 2010), experiments constraining various parameterizations related to emissions of S/IVOC precursors, volatility distribution, and chemistry including 

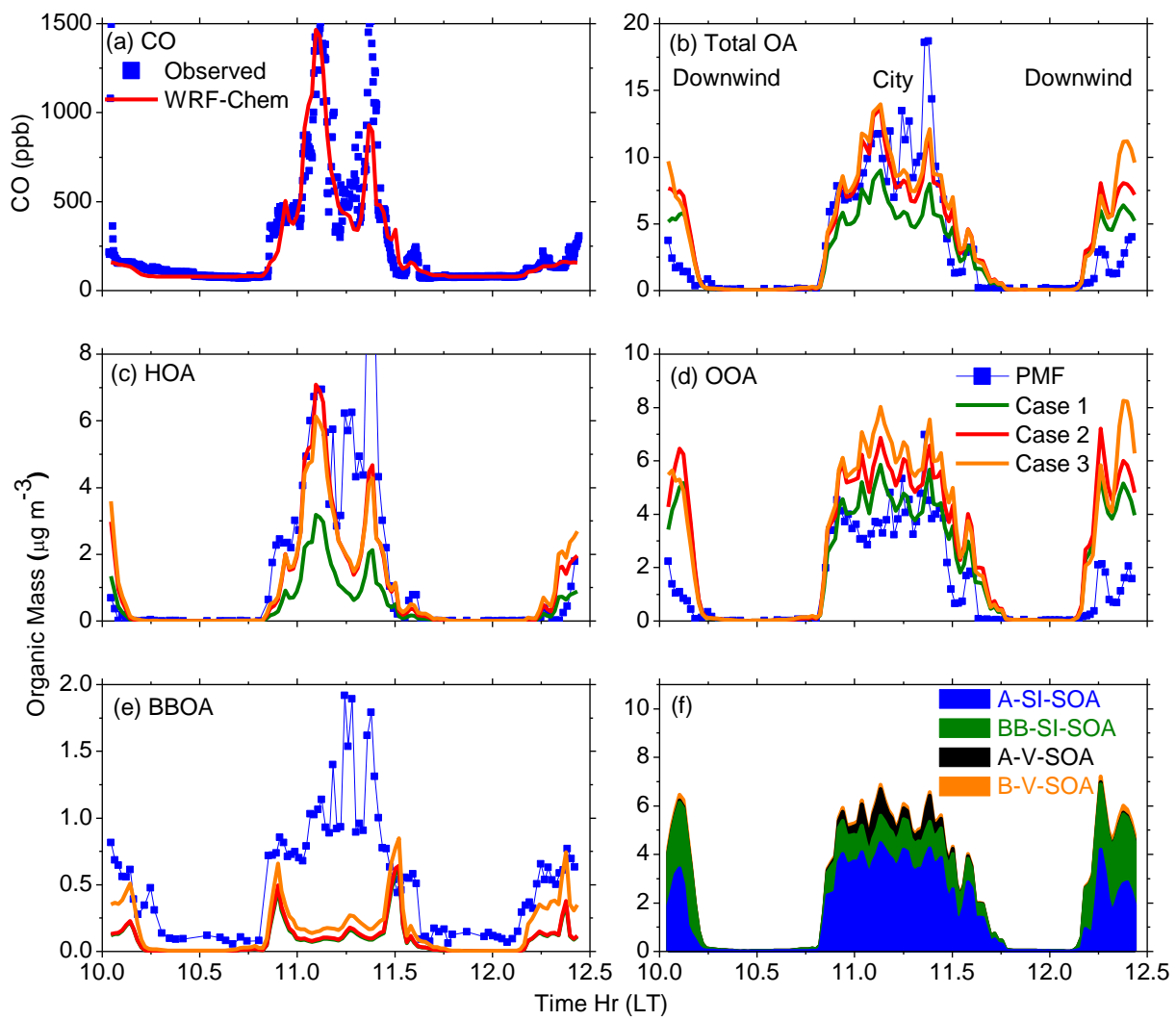

Fig. 8. Comparing WRF-Chem predictions to measurements (a) CO mixing ratios, and (b) total OA, (c) HOA, (d) OOA and (e) BBOA versus corresponding Positive matrix factorization (PMF) factors. (f) Various SOA components predicted by WRF-Chem Case 2 simulations along flight transect of G-1 on 15th of March as discussed in text. Case 1, Case 2 and Case 3 are different modeling Cases as discussed in the text. PMF data are averaged to 1 min time intervals to reduce visual clutter. In (f), blue and green denote the sum of semi-volatile and intermediate volatility SOA from anthropogenic and biomass burning sources, respectively, and black and orange denote SOA from traditional anthropogenic and biogenic sources, respectively.

functionalization, fragmentation and oligomerization reactions are needed to improve predictions of both mass and oxidation state of $\mathrm{OA}$ in the atmosphere. In addition, Vaden et al. (2011) recently showed that SOA particles in both laboratory and ambient environments evaporate much slower than predictions of kinetic models based on absorptive partitioning theory, challenging fundamental assumptions of instantaneous reversible equilibrium and liquid-like SOA behavior in SOA models. The implications of Vaden et al. (2011) study on SOA predictions needs to be evaluated in the future.

More research is also needed to make sure that total OA is accurately predicted for the right reasons: i.e. all the components of OA including HOA, OOA, and BBOA need to be right as well. In addition, models also need to capture the evolution of $\mathrm{O}: \mathrm{C}$ ratios of OA. AMS measurements during field experiments involving both ground and aircraft flights are valuable to help constrain parameters of the VBS approach. For example, we showed that biomass burning emissions are consistently under-predicted by all model cases at both ground and aircraft locations pointing to a continued need to revise biomass burning emissions in and around
Mexico City region. In addition, consistent under-prediction in HOA within the city center and most aircraft flights aloft suggest that either primary anthropogenic SVOC emissions need to be increased or SVOC emissions have a higher nonvolatile fraction than currently assumed. Also, Fig. S2 in the Supplement shows higher scatter in PMF HOA when plotted against $\mathrm{CO}$ as compared to WRF-Chem predictions. This suggests that spatial and temporal variation of emissions in 2006 MCMA inventory need to be revised. In addition, the effect of loss mechanisms such as dry deposition of S/IVOC vapors downwind need to be quantified experimentally. Karl et al. (2010) recently showed that dry deposition of oxygenated VOCs is substantially larger than previously assumed for deciduous ecosystems. Models need to account for changing dry deposition as a function of photochemical aging of organics in the atmosphere. Accurate representation of all physical and chemical processes affecting OA is necessary to get the right answers for the right reasons in climate models. 


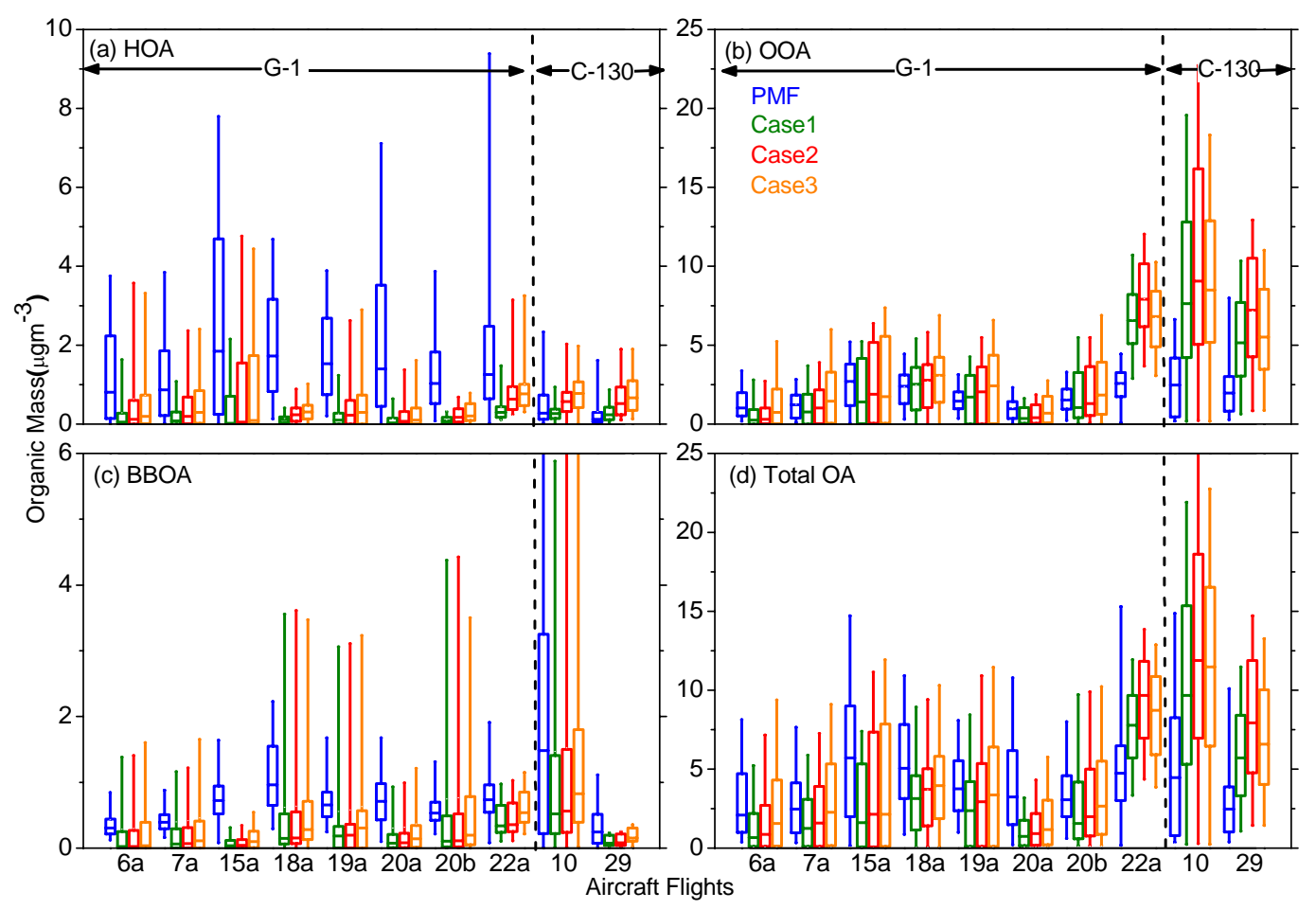

Fig. 9. Comparison of PMF components and WRF-Chem results for the 3 modeling Cases along the 8 G-1 and 2 C-130 aircraft flight tracks where horizontal lines denote median, boxes denote 25th and 75th percentiles, and whiskers denote 5th and 95th percentiles for (a) HOA (b) OOA (c) BBOA (d) Total OA.

OA and organic vapor measurements also need substantial improvements. Uncertainties in AMS measurements and subsequent PMF analysis also need to be better quantified. These uncertainties will vary spatially and temporally due to two factors. First, there were possible variations in collection efficiency among the different G-1 flights (Kleinman et al., 2008). These variations are inconsistent, however, with the good intercomparisons observed for the C-130 aircraft (DeCarlo et al., 2008) at the T0 site and the uncertainty analysis of collection efficiency (CE) in several campaigns by Middlebrook et al. (2011), which highlights the difficulty of determining AMS CE from single instrument intercomparisons in the field. Second, PMF will have difficulty separating the contribution of different $\mathrm{OA}$ factors at locations and times when markers for different factors as HOA, OOA and BBOA co-vary in the atmosphere (which often occurred during MILAGRO), especially when unit-resolution data is used as for the G-1 aircraft and the T1 site (Aiken et al., 2009). Comparing PMF results to predictions from a source-oriented modeling approach such as WRF-Chem helps to identify the range of uncertainties in both source-oriented and PMF based approaches. At the same time, information from both types of approaches needs to be combined in a consistent manner to improve OA predictions in the atmosphere. In addition to improvements of the AMS and its analysis techniques, additional real-time instruments for OA characteri- zation need to be developed and deployed, especially those that may have more detailed chemical markers for OA from different sources. Importantly, a measurement of total gasphase species with some volatility and/or chemical resolution such as O:C (analogous to the AMS) is critically needed, as otherwise no comparison of predicted vs. measured bulk gasphase species is possible, as in this study. Finally resolving the discrepancies between different non-fossil carbon measurements and performing those measurements with higher time resolution is important for better constraining model results, as discussed in Sect. S2.0 in the Supplement. In addition, several other processes such as formation of SOA from volatile species as glyoxal, increase of biogenic SOA yields in presence of anthropogenic pollution for e.g. formation of organo-sulfates, organo-nitrates and esterification processes, and SOA formation in clouds, need to be studied and included in models.

\section{Conclusions}

The WRF-Chem community model has been revised to include SOA formation coupled to the inorganic MOSAIC code for the first time. Traditional V-SOA formation using $\mathrm{NO}_{\mathrm{x}}$-dependent yields from both traditional anthropogenic and biogenic VOC precursors are included. Non-traditional 
SOA formation from S/IVOC precursors is also implemented using the volatility basis-set approach following Robinson et al. (2007). In addition to 9-species VBS approach to model SI-SOA formation from S/IVOC precursor emissions, a highly condensed 2-species VBS approach is developed and tested with respect to similarity to the detailed 9-species VBS approach. AMS measurements at ground sites and aircraft sampling during MCMA 2006 is used to evaluate WRF-Chem simulations. Results show that 2-species VBS predictions of total OA, HOA, OOA and BBOA are similar to the 9-species VBS predictions (with same S/IVOC emissions) at both ground locations ( $\mathrm{T} 0$ and $\mathrm{T} 1$ sites) and along 10 aircraft transects studied. This comprehensive evaluation includes a range of conditions from city center to downwind locations.

In addition, the 2-species VBS also predicts evolution of $\mathrm{O}: \mathrm{C}$ ratios similar to the 9-species VBS approach (within $25 \%$ ). The simplified 2 -species mechanism reduces the computational cost by a factor of 2 as compared to 9-species VBS. Thus the condensed 2-species mechanism is better suited for routine applications using computationally expensive models such as WRF-Chem running coupled cloudaerosol-meteorology as well as global models. Validating the 2-species to the 9-species VBS predictions is an essential first step to using these highly condensed SOA mechanisms designed to represent the full complexity of information (both mass and oxidation state of OA). However, as discussed in the text both 9-species and 2-species VBS formalisms do not simulate SOA well. Future studies need to re-evaluate either of these VBS approaches as new experimental data on SOA formation and atmospheric evolution, and emissions of S/IVOC precursors are available, which is beyond the scope of this study.

In the future, we also plan to evaluate the impact of evolving mass and oxidation state (O:C ratio) of OA on aerosol optical properties (e.g. refractive index), hygroscopicity and CCN activity, and dry deposition of S/IVOC precursors varying with O:C ratios by means of WRF-Chem using more recent field and laboratory data. Additional well-coordinated field and laboratory measurements are needed to constrain these parameterizations as a function of photochemical aging of $\mathrm{OA}$ in the atmosphere.

\section{Supplementary material related to this article is available online at: http://www.atmos-chem-phys.net/11/6639/2011/ acp-11-6639-2011-supplement.pdf.}

Acknowledgements. We thank Miguel Zavala and Luisa Molina (Molina Center for Energy and the Environment) for providing the most recent MCMA emissions inventory, Christine Wiedinmyer (National Center for Atmospheric Research) for providing the biomass burning inventory, Sebastien Dusanter and Phil Stevens (Indiana Univ.) for $\mathrm{OH}$ data, Larry Kleinman (Brookhaven
National Laboratory), Manjula Canagaratna (Aerodyne Research Inc.), Lizbeth Alexander (PNNL), and Peter DeCarlo, Allison Aiken, and Ingrid Ulbrich (Univ. of Colorado) for providing AMS data, and Georg Grell and Steven Peckham (NOAA / Earth System Research Laboratory) for their support of WRF-Chem. JLJ was supported by NOAA NA08OAR4310565. This research was supported by the US DOE's Atmospheric Sciences Program of the Office of Biological and Environmental Research (OBER) under Contract DE-AC06-76RLO 1830 at Pacific Northwest National Laboratory (PNNL). PNNL is operated for the US DOE by Battelle Memorial Institute.

Edited by: A. Baklanov

\section{References}

Aiken, A. C., Decarlo, P. F., Kroll, J. H., Worsnop, D. R., Huffman, J. A., Docherty, K. S., Ulbrich, I. M., Mohr, C., Kimmel, J. R., Sueper, D., Sun, Y., Zhang, Q., Trimborn, A., Northway, M., Ziemann, P. J., Canagaratna, M. R., Onasch, T. B., Alfarra, M. R., Prevot, A. S. H., Dommen, J., Duplissy, J., Metzger, A., Baltensperger, U., and Jimenez, J. L.: O/C and OM/OC ratios of primary, secondary, and ambient organic aerosols with highresolution time-of-flight aerosol mass spectrometry, Environ. Sci. Technol., 42, 4478-4485, doi:10.1021/es703009q, 2008.

Aiken, A. C., Salcedo, D., Cubison, M. J., Huffman, J. A., DeCarlo, P. F., Ulbrich, I. M., Docherty, K. S., Sueper, D., Kimmel, J. R., Worsnop, D. R., Trimborn, A., Northway, M., Stone, E. A., Schauer, J. J., Volkamer, R. M., Fortner, E., de Foy, B., Wang, J., Laskin, A., Shutthanandan, V., Zheng, J., Zhang, R., Gaffney, J., Marley, N. A., Paredes-Miranda, G., Arnott, W. P., Molina, L. T., Sosa, G., and Jimenez, J. L.: Mexico City aerosol analysis during MILAGRO using high resolution aerosol mass spectrometry at the urban supersite (T0) - Part 1: Fine particle composition and organic source apportionment, Atmos. Chem. Phys., 9, 66336653, doi:10.5194/acp-9-6633-2009, 2009.

Aiken, A. C., de Foy, B., Wiedinmyer, C., DeCarlo, P. F., Ulbrich, I. M., Wehrli, M. N., Szidat, S., Prevot, A. S. H., Noda, J., Wacker, L., Volkamer, R., Fortner, E., Wang, J., Laskin, A., Shutthanandan, V., Zheng, J., Zhang, R., Paredes-Miranda, G., Arnott, W. P., Molina, L. T., Sosa, G., Querol, X., and Jimenez, J. L.: Mexico city aerosol analysis during MILAGRO using high resolution aerosol mass spectrometry at the urban supersite (T0) - Part 2: Analysis of the biomass burning contribution and the non-fossil carbon fraction, Atmos. Chem. Phys., 10, 5315-5341, doi:10.5194/acp-10-5315-2010, 2010.

Akagi, S. K., Yokelson, R. J., Wiedinmyer, C., Alvarado, M. J., Reid, J. S., Karl, T., Crounse, J. D., and Wennberg, P. O.: Emission factors for open and domestic biomass burning for use in atmospheric models, Atmos. Chem. Phys., 11, 4039-4072, doi:10.5194/acp-11-4039-2011, 2011.

Andreae, M. O. and Merlet, P.: Emission of trace gases and aerosols from biomass burning, Glob. Biogeochem. Cy., 15, 955-966, 2001.

Capouet, M., Mueller, J. F., Ceulemans, K., Compernolle, S., Vereecken, L., and Peeters, J.: Modeling aerosol formation in alpha-pinene photo-oxidation experiments, J. Geophys. Res.Atmos., 113, D02308 doi:10.1029/2007jd008995, 2008. 
Cappa, C. D. and Jimenez, J. L.: Quantitative estimates of the volatility of ambient organic aerosol, Atmos. Chem. Phys., 10, 5409-5424, doi:10.5194/acp-10-5409-2010, 20doi:10.

Carlton, A. G., Bhave, P. V., Napelenok, S. L., Edney, E. O., Sarwar, G., Pinder, R. W., Pouliot, G. A., and Houyoux, M.: Model Representation of Secondary Organic Aerosol in CMAQv4.7, Environ. Sci. Technol., 44(22), 8553-8560, 2010.

Carter, W.P.L.: Documentation of the SAPRC-99 Chemical Mechanism for VOC Reactivity Assessment, Draft report to the California Air Resources Board, Contracts 92-329 and 95-308, 8 May, available at: http://www.cert.ucr.edu/ carter/absts.htm\#saprc99, 2000a.

Carter, W.P.L.: Implementation of the SAPRC-99 Chemical Mechanism into the Models-3 Framework, Report to the United States Environmental Protection Agency, 29 January, available at: http: //www.cert.ucr.edu/ $\sim$ carter/absts.htm\#s99mod3, $2000 \mathrm{~b}$.

Crounse, J. D., DeCarlo, P. F., Blake, D. R., Emmons, L. K., Campos, T. L., Apel, E. C., Clarke, A. D., Weinheimer, A. J., McCabe, D. C., Yokelson, R. J., Jimenez, J. L., and Wennberg, P. O.: Biomass burning and urban air pollution over the Central Mexican Plateau, Atmos. Chem. Phys., 9, 4929-4944, doi:10.5194/acp-9-4929-2009, 2009.

Damian, V., Sandu, A., Damian, M., Potra, F., and Carmichael, G. R.: The kinetic preprocessor KPP - a software environment for solving chemical kinetics, Comput. Chem. Eng., 26, 1567-1579, 2002.

de Gouw, J. A., Middlebrook, A. M., Warneke, C., Goldan, P. D., Kuster, W. C., Roberts, J. M., Fehsenfeld, F. C., Worsnop, D. R., Canagaratna, M. R., Pszenny, A. A. P., Keene, W. C., Marchewka, M., Bertman, S. B., and Bates, T. S.: Budget of organic carbon in a polluted atmosphere: Results from the New England Air Quality Study in 2002, J. Geophys. Res.-Atmos., 110, D16305, doi:10.1029/2004jd005623, 2005.

DeCarlo, P. F., Dunlea, E. J., Kimmel, J. R., Aiken, A. C., Sueper, D., Crounse, J., Wennberg, P. O., Emmons, L., Shinozuka, Y., Clarke, A., Zhou, J., Tomlinson, J., Collins, D. R., Knapp, D., Weinheimer, A. J., Montzka, D. D., Campos, T., and Jimenez, J. L.: Fast airborne aerosol size and chemistry measurements above Mexico City and Central Mexico during the MILAGRO campaign, Atmos. Chem. Phys., 8, 4027-4048, doi:10.5194/acp8-4027-2008, 2008.

Donahue, N. M., Robinson, A. L., Stanier, C. O., and Pandis, S. N.: Coupled partitioning, dilution, and chemical aging of semivolatile organics, Environ. Sci. Technol., 40, 2635-2643, doi:10.1021/es052297c, 2006.

Dusanter, S., Vimal, D., Stevens, P. S., Volkamer, R., and Molina, L. T.: Measurements of $\mathrm{OH}$ and $\mathrm{HO} 2$ concentrations during the MCMA-2006 field campaign - Part 1: Deployment of the Indiana University laser-induced fluorescence instrument, Atmos. Chem. Phys., 9, 1665-1685, doi:10.5194/acp-9-1665-2009, 2009.

Dzepina, K., Volkamer, R. M., Madronich, S., Tulet, P., Ulbrich, I. M., Zhang, Q., Cappa, C. D., Ziemann, P. J., and Jimenez, J. L.: Evaluation of recently-proposed secondary organic aerosol models for a Case study in Mexico City, Atmos. Chem. Phys., 9, 5681-5709, doi:10.5194/acp-9-5681-2009, 2009.

Dzepina, K., Cappa, C. D., Volkamer, R. M., Madronich, S., DeCarlo, P. F., Zaveri, R. A., and Jimenez, J. L.: Modeling the multiday evolution and aging of secondary organic aerosol during MILAGRO 2006, Environ. Sci. Technol., 45, 3496-3503, doi:10.1021/es103186f, 2011.

Emmons, L. K., Apel, E. C., Lamarque, J. F., Hess, P. G., Avery, M., Blake, D., Brune, W., Campos, T., Crawford, J., DeCarlo, P. F., Hall, S., Heikes, B., Holloway, J., Jimenez, J. L., Knapp, D. J., Kok, G., Mena-Carrasco, M., Olson, J., O’Sullivan, D., Sachse, G., Walega, J., Weibring, P., Weinheimer, A., and Wiedinmyer, C.: Impact of Mexico City emissions on regional air quality from MOZART-4 simulations, Atmos. Chem. Phys., 10, 6195-6212, doi:10.5194/acp-10-6195-2010, 2010.

Fast, J. D., de Foy, B., Acevedo Rosas, F., Caetano, E., Carmichael, G., Emmons, L., McKenna, D., Mena, M., Skamarock, W., Tie, X., Coulter, R. L., Barnard, J. C., Wiedinmyer, C., and Madronich, S.: A meteorological overview of the MILAGRO field campaigns, Atmos. Chem. Phys., 7, 2233-2257, doi:10.5194/acp-7-2233-2007, 2007.

Fast, J., Aiken, A. C., Allan, J., Alexander, L., Campos, T., Canagaratna, M. R., Chapman, E., DeCarlo, P. F., de Foy, B., Gaffney, J., de Gouw, J., Doran, J. C., Emmons, L., Hodzic, A., Herndon, S. C., Huey, G., Jayne, J. T., Jimenez, J. L., Kleinman, L., Kuster, W., Marley, N., Russell, L., Ochoa, C., Onasch, T. B., Pekour, M., Song, C., Ulbrich, I. M., Warneke, C., WelshBon, D., Wiedinmyer, C., Worsnop, D. R., Yu, X. Y., and Zaveri, R.: Evaluating simulated primary anthropogenic and biomass burning organic aerosols during MILAGRO: implications for assessing treatments of secondary organic aerosols, Atmos. Chem. Phys., 9, 6191-6215, 2009, http://www.atmos-chem-phys.net/9/6191/2009/.

Fast, J. D., Gustafson W.I. Jr., Chapman E.G., Easter R.C., Rishel J., Zaveri R.A., Grell G., and Barth M. : The Aerosol Modeling Testbed: A community tool to objectively evaluate aerosol process modules, B. Am. Meteorol. Soc., 92, 343-360, 2011.

Friedl, M. A., Sulla-Menashe, D., Tan, B., Schneider, A., Ramankutty, N., Sibley, A., and Huang, X. M.: MODIS Collection 5 global land cover: Algorithm refinements and characterization of new datasets, Remote Sens. Environ., 114, 168-182, doi:10.1016/j.rse.2009.08.016, 2010.

Giglio, L., Descloitres, J., Justice, C. O., and Kaufman, Y. J.: An enhanced contextual fire detection algorithm for MODIS, Remote Sens. Environ., 87, 273-282, doi:10.1016/s00344257(03)00184-6, 2003.

Goldstein, A. H. and Galbally, I. E.: Known and unexplored organic constituents in the earth's atmosphere, Environ. Sci. Technol., 41, 1514-1521, 2007.

Grell, G. A., Knoche, R., Peckham, S. E., and McKeen, S. A.: Online versus offline air quality modeling on cloud-resolving scales, Geophys. Res. Lett., 31, L16117, doi:10.1029/2004g1020175, 2004.

Grell, G. A., Peckham, S. E., Schmitz, R., McKeen, S. A., Frost, G., Skamarock, W. C., and Eder, B.: Fully coupled "online" chemistry within the WRF model, Atmos. Environ., 39, 6957-6975, doi:10.1016/j.atmosenv.2005.04.027, 2005.

Grieshop, A. P., Logue, J. M., Donahue, N. M., and Robinson, A. L.: Laboratory investigation of photochemical oxidation of organic aerosol from wood fires 1: measurement and simulation of organic aerosol evolution, Atmos. Chem. Phys., 9, 1263-1277, doi:10.5194/acp-9-1263-2009, 2009.

Guenther, A., Karl, T., Harley, P., Wiedinmyer, C., Palmer, P. I., and Geron, C.: Estimates of global terrestrial isoprene emissions using MEGAN (Model of Emissions of Gases and Aerosols from 
Nature), Atmos. Chem. Phys., 6, 3181-3210, doi:10.5194/acp-63181-2006, 2006.

Hallquist, M., Wenger, J. C., Baltensperger, U., Rudich, Y., Simpson, D., Claeys, M., Dommen, J., Donahue, N. M., George, C., Goldstein, A. H., Hamilton, J. F., Herrmann, H., Hoffmann, T., Iinuma, Y., Jang, M., Jenkin, M. E., Jimenez, J. L., Kiendler-Scharr, A., Maenhaut, W., McFiggans, G., Mentel, Th. F., Monod, A., Prvt, A. S. H., Seinfeld, J. H., Surratt, J. D., Szmigielski, R., and Wildt, J.: The formation, properties and impact of secondary organic aerosol: current and emerging issues, Atmos. Chem. Phys., 9, 5155-5236, doi:10.5194/acp-95155-2009, 2009.

Heald, C. L., Jacob, D. J., Park, R. J., Russell, L. M., Huebert, B. J., Seinfeld, J. H., Liao, H., and Weber, R. J.: A large organic aerosol source in the free troposphere missing from current models, Geophys. Res. Lett., 32, L18809, doi:10.1029/2005g1023831, 2005.

Henze, D. K. and Seinfeld, J. H.: Global secondary organic aerosol from isoprene oxidation, Geophys. Res. Lett., 33, L09812, doi:10.1029/2006g1025976, 2006.

Hildebrandt, L., Donahue, N. M., and Pandis, S. N.: High formation of secondary organic aerosol from the photo-oxidation of toluene, Atmos. Chem. Phys., 9, 2973-2986, doi:10.5194/acp-92973-2009, 2009.

Hodzic, A., Jimenez, J. L., Madronich, S., Aiken, A. C., Bessagnet, B., Curci, G., Fast, J., Lamarque, J.-F., Onasch, T. B., Roux, G., Schauer, J. J., Stone, E. A., and Ulbrich, I. M.: Modeling organic aerosols during MILAGRO: importance of biogenic secondary organic aerosols, Atmos. Chem. Phys., 9, 6949-6981, doi:10.5194/acp-9-6949-2009, 2009.

Hodzic, A., Jimenez, J. L., Madronich, S., Canagaratna, M. R., DeCarlo, P. F., Kleinman, L., and Fast, J.: Modeling organic aerosols in a megacity: potential contribution of semi-volatile and intermediate volatility primary organic compounds to secondary organic aerosol formation, Atmos. Chem. Phys., 10, 5491-5514, doi:10.5194/acp-10-5491-2010, 2010.

Hoelzemann, J. J., Schultz, M. G., Brasseur, G. P., Granier, C., and Simon, M.: Global Wildland Fire Emission Model (GWEM): Evaluating the use of global area burnt satellite data, J. Geophys. Res.-Atmos., 109, D14s04 doi:10.1029/2003jd003666, 2004.

Jimenez, J. L., Canagaratna, M. R., Donahue, N. M., Prevot, A. S. H., Zhang, Q., Kroll, J. H., DeCarlo, P. F., Allan, J. D., Coe, H., Ng, N. L., Aiken, A. C., Docherty, K. S., Ulbrich, I. M., Grieshop, A. P., Robinson, A. L., Duplissy, J., Smith, J. D., Wilson, K. R., Lanz, V. A., Hueglin, C., Sun, Y. L., Tian, J., Laaksonen, A., Raatikainen, T., Rautiainen, J., Vaattovaara, P., Ehn, M., Kulmala, M., Tomlinson, J. M., Collins, D. R., Cubison, M. J., Dunlea, E. J., Huffman, J. A., Onasch, T. B., Alfarra, M. R., Williams, P. I., Bower, K., Kondo, Y., Schneider, J., Drewnick, F., Borrmann, S., Weimer, S., Demerjian, K., Salcedo, D., Cottrell, L., Griffin, R., Takami, A., Miyoshi, T., Hatakeyama, S., Shimono, A., Sun, J. Y., Zhang, Y. M., Dzepina, K., Kimmel, J. R., Sueper, D., Jayne, J. T., Herndon, S. C., Trimborn, A. M., Williams, L. R., Wood, E. C., Middlebrook, A. M., Kolb, C. E., Baltensperger, U., and Worsnop, D. R.: Evolution of Organic Aerosols in the Atmosphere, Science, 326, 1525-1529, doi:10.1126/science.1180353, 2009.

Karl, T., Harley, P., Emmons, L., Thornton, B., Guenther, A., Basu, C., Turnipseed, A., and Jardine, K.: Efficient Atmospheric
Cleansing of Oxidized Organic Trace Gases by Vegetation, Science, 330, 816-819, doi:10.1126/science.1192534, 20doi:10.

Kleinman, L. I., Springston, S. R., Daum, P. H., Lee, Y.-N., Nunnermacker, L. J., Senum, G. I., Wang, J., Weinstein-Lloyd, J., Alexander, M. L., Hubbe, J., Ortega, J., Canagaratna, M. R., and Jayne, J.: The time evolution of aerosol composition over the Mexico City plateau, Atmos. Chem. Phys., 8, 1559-1575, doi:10.5194/acp-8-1559-2008, 2008.

Kroll, J. H., Smith, J. D., Che, D. L., Kessler, S. H., Worsnop, D. R., and Wilson, K. R.: Measurement of fragmentation and functionalization pathways in the heterogeneous oxidation of oxidized organic aerosol, Phys. Chem. Chem. Phys., 11, 8005-8014, doi:10.1039/b905289e, 2009.

Lane, T. E., Donahue, N. M., and Pandis, S. N.: Effect of $\mathrm{NO}_{\mathrm{x}}$ on secondary organic aerosol concentrations, Environ. Sci. Technol., 42, 6022-6027, doi:10.1021/es703225a, 2008.

Middlebrook, A. M., Bahreini, R., Jimenez, J. L., and Canagaratna, M.: Evaluation of composition dependent collection efficiencies for the Aerodyne Aerosol Mass Spectrometer using field data, Aerosol Sci. Tech., submitted, 2011.

MODIS Rapid Response Project: MODIS Hotspot/Active Fire Detections, NASA/University of Maryland, Fire Information for Resource Management System, http://maps.geog.umd.edu, last access: 2011.

Mohr, C., Huffman, J. A., Cubison, M. J., Aiken, A. C., Docherty, K. S., Kimmel, J. R., Ulbricht, I. M., Hannigan, M., and Jimenez, J. L.: Characterization of Primary Organic Aerosol Emissions from Meat Cooking, Trash Burning, and Motor Vehicles with High-Resolution Aerosol Mass Spectrometry and Comparison with Ambient and Chamber Observations, Environ. Sci. Technol., 43, 2443-2449, doi:10.1021/es8011518, 2009.

Murphy, D. M., Cziczo, D. J., Froyd, K. D., Hudson, P. K., Matthew, B. M., Middlebrook, A. M., Peltier, R. E., Sullivan, A., Thomson, D. S., and Weber, R. J.: Single-particle mass spectrometry of tropospheric aerosol particles, J. Geophys. Res.-Atmos., 111, D23s32 doi:10.1029/2006jd007340, 2006.

Ng, N. L., Chhabra, P. S., Chan, A. W. H., Surratt, J. D., Kroll, J. H., Kwan, A. J., McCabe, D. C., Wennberg, P. O., Sorooshian, A., Murphy, S. M., Dalleska, N. F., Flagan, R. C., and Seinfeld, J. H.: Effect of NOx level on secondary organic aerosol (SOA) formation from the photooxidation of terpenes, Atmos. Chem. Phys., 7, 5159-5174, doi:10.5194/acp-7-5159-2007, 2007.

Ng, N. L., Kroll, J. H., Chan, A. W. H., Chhabra, P. S., Flagan, R. C., and Seinfeld, J. H.: Secondary organic aerosol formation from $m$-xylene, toluene, and benzene, Atmos. Chem. Phys., 7, 3909-3922, doi:10.5194/acp-7-3909-2007, 2007.

Ng, N. L., Canagaratna, M. R., Zhang, Q., Jimenez, J. L., Tian, J., Ulbrich, I. M., Kroll, J. H., Docherty, K. S., Chhabra, P. S., Bahreini, R., Murphy, S. M., Seinfeld, J. H., Hildebrandt, L., Donahue, N. M., DeCarlo, P. F., Lanz, V. A., Prevot, A. S. H., Dinar, E., Rudich, Y., and Worsnop, D. R.: Organic aerosol components observed in Northern Hemispheric datasets from Aerosol Mass Spectrometry, Atmos. Chem. Phys., 10, 46254641, doi:10.5194/acp-10-4625-2010, 2010.

Pun, B. K., Seigneur, C., and Lohman, K.: Modeling secondary organic aerosol formation via multiphase partitioning with molecular data, Environ. Sci. Technol., 40, 4722-4731, doi:10.1021/es0522736, 2006.

Pye, H. O. T. and Seinfeld, J. H.: A global perspective on aerosol 
from low-volatility organic compounds, Atmos. Chem. Phys., 10, 4377-4401, doi:10.5194/acp-10-4377-2010, 2010.

Robinson, A. L., Donahue, N. M., Shrivastava, M. K., Weitkamp, E. A., Sage, A. M., Grieshop, A. P., Lane, T. E., Pierce, J. R., and Pandis, S. N.: Rethinking organic aerosols: Semivolatile emissions and photochemical aging, Science, 315, 1259-1262, doi:10.1126/science.1133061, 2007.

Shrivastava, M. K., Lipsky, E. M., Stanier, C. O., and Robinson, A. L.: Modeling semivolatile organic aerosol mass emissions from combustion systems, Environ. Sci. Technol., 40, 26712677, doi:10.1021/es0522231, 2006.

Shrivastava, M. K., Lane, T. E., Donahue, N. M., Pandis, S. N., and Robinson, A. L.: Effects of gas particle partitioning and aging of primary emissions on urban and regional organic aerosol concentrations, J. Geophys. Res.-Atmos., 113, D18301, doi:10.1029/2007jd009735, 2008.

Slowik, J. G., Stroud, C., Bottenheim, J. W., Brickell, P. C., Chang, R. Y.-W., Liggio, J., Makar, P. A., Martin, R. V., Moran, M. D., Shantz, N. C., Sjostedt, S. J., van Donkelaar, A., Vlasenko, A., Wiebe, H. A., Xia, A. G., Zhang, J., Leaitch, W. R., and Abbatt, J. P. D.: Characterization of a large biogenic secondary organic aerosol event from eastern Canadian forests, Atmos. Chem. Phys., 10, 2825-2845, doi:10.5194/acp-10-2825-2010, 2010.

Song, J., Lei, W., Bei, N., Zavala, M., de Foy, B., Volkamer, R., Cardenas, B., Zheng, J., Zhang, R., and Molina, L. T.: Ozone response to emission changes: a modeling study during the MCMA-2006/MILAGRO Campaign, Atmos. Chem. Phys., 10, 3827-3846, doi:10.5194/acp-10-3827-2010, 2010.

Tsimpidi, A. P., Karydis, V. A., Zavala, M., Lei, W., Molina, L., Ulbrich, I. M., Jimenez, J. L., and Pandis, S. N.: Evaluation of the volatility basis-set approach for the simulation of organic aerosol formation in the Mexico City metropolitan area, Atmos. Chem. Phys., 10, 525-546, doi:10.5194/acp-10-525-2010, 2010.

Tunved, P., Hansson, H. C., Kerminen, V. M., Strom, J., Dal Maso, M., Lihavainen, H., Viisanen, Y., Aalto, P. P., Komppula, M., and Kulmala, M.: High natural aerosol loading over boreal forests, Science, 312, 261-263, doi:10.1126/science.1123052, 2006.
Ulbrich, I. M., Canagaratna, M. R., Zhang, Q., Worsnop, D. R., and Jimenez, J. L.: Interpretation of organic components from Positive Matrix Factorization of aerosol mass spectrometric data, Atmos. Chem. Phys., 9, 2891-2918, 2009, http://www.atmos-chem-phys.net/9/2891/2009/.

Vaden, T. D., Imre, D., Beranek, J., Shrivastava, M., and Zelenyuk, A.: Evaporation kinetics and phase of laboratory and ambient secondary organic aerosol, P. Natl. Acad. Sci. USA, 108(6), 2190-2195, doi:10.1073/pnas.1013391108, 2011.

Volkamer, R., Jimenez, J. L., San Martini, F., Dzepina, K., Zhang, Q., Salcedo, D., Molina, L. T., Worsnop, D. R., and Molina, M. J.: Secondary organic aerosol formation from anthropogenic air pollution: Rapid and higher than expected, Geophys. Res. Lett., 33, L17811, doi:10.1029/2006gl026899, 2006.

Wesely, M. L.: Parameterization of surface res istances to gaseous dry deposition in regional scale numerical models, Atmos. Environ., 23, 1293-1304, 1989.

Wiedinmyer, C., Quayle, B., Geron, C., Belote, A., McKenzie, D., Zhang, X. Y., O'Neill, S., and Wynne, K. K.: Estimating emissions from fires in North America for air quality modeling, Atmos. Environ., 40, 3419-3432, doi:10.1016/j.atmosenv.2006.02.010, 2006.

Zaveri, R. A., Easter, R. C., Fast, J. D., and Peters, L. K.: Model for Simulating Aerosol Interactions and Chemistry (MOSAIC), J. Geophys. Res.-Atmos., 113, D13204, doi:10.1029/2007jd008782, 2008.

Zhang, Q., Jimenez, J. L., Canagaratna, M. R., Allan, J. D., Coe, H., Ulbrich, I., Alfarra, M. R., Takami, A., Middlebrook, A. M., Sun, Y. L., Dzepina, K., Dunlea, E., Docherty, K., DeCarlo, P. F., Salcedo, D., Onasch, T., Jayne, J. T., Miyoshi, T., Shimono, A., Hatakeyama, S., Takegawa, N., Kondo, Y., Schneider, J., Drewnick, F., Borrmann, S., Weimer, S., Demerjian, K., Williams, P., Bower, K., Bahreini, R., Cottrell, L., Griffin, R. J., Rautiainen, J., Sun, J. Y., Zhang, Y. M., and Worsnop, D. R.: Ubiquity and dominance of oxygenated species in organic aerosols in anthropogenically-influenced Northern Hemisphere midlatitudes, Geophys. Res. Lett., 34, L13801, doi:10.1029/2007g1029979, 2007. 